Review

\title{
Deciphering complement mechanisms: The contributions of structural biology
}

\author{
Gérard J. Arlaud $^{\mathrm{a}, *, 1}$, Paul N. Barlow ${ }^{\mathrm{b}, 1}$, Christine Gaboriaud ${ }^{\mathrm{a}, 1}$, \\ Piet Gros ${ }^{\mathrm{c}, 1}$, Sthanam V.L. Narayana ${ }^{\mathrm{d}, 1}$ \\ a Institut de Biologie Structurale Jean-Pierre Ebel, CEA, CNRS, Université Joseph Fourier, 41 rue Jules Horowitz, F-38027 Grenoble, France \\ ${ }^{\mathrm{b}}$ Biomolecular NMR Unit, Schools of Biological Sciences and Chemistry, University of Edinburgh, Edinburgh, UK \\ ${ }^{\mathrm{c}}$ Crystal and Structural Chemistry, Bijvoet Center for Biomolecular Research, Faculty of Sciences, Utrecht University, Utrecht, The Netherlands \\ ${ }^{\mathrm{d}}$ Center for Biophysical Sciences and Engineering, School of Optometry, University of Alabama at Birmingham, Birmingham, AL, USA
}

Received 2 June 2007

\begin{abstract}
Since the resolution of the first three-dimensional structure of a complement component in 1980, considerable efforts have been put into the investigation of this system through structural biology techniques, resulting in about a hundred structures deposited in the Protein Data Bank by the beginning of 2007. By revealing its mechanisms at the atomic level, these approaches significantly improve our understanding of complement, opening the way to the rational design of specific inhibitors. This review is co-authored by some of the researchers currently involved in the structural biology of complement and its purpose is to illustrate, through representative examples, how X-ray crystallography and NMR techniques help us decipher the many sophisticated mechanisms that underlie complement functions.
\end{abstract}

(C) 2007 Elsevier Ltd. All rights reserved.

Keywords: Complement; Structures; X-ray crystallography; NMR

\section{Introduction}

By comparison with other related biological systems such as blood coagulation, investigation of the structure and mechanism of action of complement proteins through the use of structural biology techniques began relatively late. The first three-dimensional structure of a complement component to be published was that of human C3a, which was solved in 1980 by X-ray crystallography (Huber et al., 1980). The solution structures of human C5a and of the 16th complement control protein (CCP) module from human factor $\mathrm{H}$, both determined by NMR

Abbreviations: aHUS, atypical haemolytic uremic syndrome; AMD, age-related macular degeneration; CCP, complement control protein; CUB, $\mathrm{C} 1 \mathrm{r} / \mathrm{C} 1 \mathrm{~s}$; Uegf; bone morphogenetic protein-1; GAG, glycosaminoglycan; $\mathrm{MG}$, macroglobulin; RBD, receptor binding domain; RCA, regulators of complement activation; SP, serine protease; TED, thioester-containing domain; vWFA, von Willebrand factor type A

* Corresponding author. Tel.: +3343878 49 81; fax: +334 38785494

E-mail address: arlaud@ibs.fr (G.J. Arlaud).

1 All authors contributed equally to this review. spectroscopy, were reported about 10 years later (Zuiderweg et al., 1989; Norman et al., 1991). The next X-ray crystallography structure to be solved was that of human factor $\mathrm{D}$, the smallest of the proteases involved in complement activation (Narayana et al., 1994). Since these pioneering studies, considerable progress has been made, as can be judged from the number of complement protein structures deposited in the Protein Data Bank, which was approximately a hundred at the beginning of 2007. Because the majority of complement proteins have a modular structure and exhibit flexibility at intermodular junctions, they generally prove refractory to X-ray crystallography analysis when studied as whole molecules. NMR spectra are difficult to interpret for larger proteins $(>30 \mathrm{kDa})$, especially if they are extended in shape. Thus, only a few of the deposited structures are of complete proteins, and most of them correspond to functional fragments or domains. A remarkable exception to this rule is the structure of the large protein C3 (1641 residues, 13 domains), which was recently solved by X-ray crystallography (Janssen et al., 2005; Fredslund et al., 2006).

Taken together, the structures currently available provide precise insights, at the atomic level, into many of the mechanisms 
that underlie complement function. This review is co-authored by some of the researchers currently investigating the atomicresolution structures of complement proteins by either X-ray crystallography or NMR spectroscopy. Its purpose is to illustrate, through representative examples, how structural biology improves our understanding of the complement system by revealing its intimate mechanisms.

\section{Structural determinants for the sensing properties of human ficolins}

Ficolins play a role in innate immunity as recognition molecules. They sense conserved molecular markers exposed at the surface of microbes and thereby trigger effector mechanisms such as enhanced phagocytosis and inflammation. Ficolins are found in a wide variety of animals ranging from invertebrates to mammals. They are soluble oligomeric proteins with lectin-like activity, assembled from collagen fibers extended by fibrinogen-like recognition domains (Fig. 1A). Like mannanbinding lectin (MBL), they can activate the lectin pathway of complement through the associated MBL-associated serine proteases (MASPs) (Matsushita and Fujita, 2001). In order to decipher the structural determinants for their binding specificity, we have investigated the X-ray structures of the recognition domain of the two human plasmatic ficolins, namely L- and $\mathrm{H}$ ficolins. Their fibrinogen-like domains spontaneously associate as trimers, the resulting recognition domains having three-lobed structures with clefts separating the distal parts of the protomers (Fig. 1A). The semi-open ficolin structure is thus intermediate between the compact assembly seen in the complement protein C1q (Gaboriaud et al., 2003), where subunits associate through an extensive interface, and the wide open structure of the MBL carbohydrate recognition domain (Weis and Drickamer, 1994; Sheriff et al., 1994). Thus, in contrast to MBL, there is no need for a "neck" region between the collagen-like fibers and the recognition domain to achieve the proper trimeric assembly.

Our main objective was to obtain structures of the domains in complex with various model ligands, in order to decipher the structural basis for their interactions at the atomic level. The questions addressed were the following: Is there a single binding site in each monomer and how is it able (or not) to sense diverse chemical targets? To what chemical motif does it bind? The most extensive study was performed with L-ficolin because of its wider recognition spectrum. Indeed, L-ficolin is able to recognise various capsulated bacteria (Matsushita and Fujita, 2001; Krarup et al., 2005) and it exhibits binding specificity for diverse ligands such as lipoteichoic acid (a specific marker of the surface of gram-positive bacteria; Lynch et al., 2004), 1,3$\beta$-D-Glucan (a specific marker of the yeast surface; Ma et al., 2004), and the capsular antigen of type III group B Streptococci (Aoyagi et al., 2005). In contrast, the related H-ficolin has only been reported to bind to Aerococcus viridans and to D-fucose or galactose molecules (Garlatti et al., 2007).

Quite unexpectedly, several different ligand-binding sites were observed in the ficolins. A single outer S1 binding pocket is found in $\mathrm{H}$-ficolin, homologous to a site also identified in the invertebrate tachylectin 5A (Kairies et al., 2001). In addition to
$\mathrm{S} 1$, three other sites, called S2, S3, and S4 were discovered in L-ficolin (Fig. 1). Together, they define a continuous recognition surface which enables L-ficolin to sense various acetylated and neutral carbohydrate markers in the context of extended polysaccharides, as found on microbial or apoptotic surfaces (Garlatti et al., 2007). This study thus provides the first structural evidence that the ability of L-ficolin to sense elongated molecules of diverse chemical nature arises from the presence of an extended binding area. This conclusion is derived from several contrasting observations concerning the binding of L-ficolin to neutral carbohydrates and acetylated compounds, which will be briefly summarized. The ability of L-ficolin to bind elongated ligands is best illustrated in Fig. 1B, where a four-residue $\beta$-D-glucan molecule, a specific marker of yeast surfaces, is coordinated by an extended interaction network involving residues contributed by both its $\mathrm{S} 3$ and $\mathrm{S} 4$ sub-sites. This differs significantly from the recognition mechanism of MBL, which only binds to a terminal carbohydrate residue. The lectin-like activity of L-ficolin is further illustrated by the numerous specific $\mathrm{H}$-bond interactions stabilizing a galactose molecule bound in its inner S2 sub-site (Fig. 1C). This interaction provides a template for the recognition of terminal galactose residues that are possibly transiently exposed on apoptotic cell surfaces (Garlatti et al., 2007). In contrast, the established specificity of L-ficolin for acetylated compounds is not explained by a single mode of interaction at the atomic level (Fig. 1D and E). Instead, recognition of these molecules appears to involve minimal structural requirement for the acetyl group, and virtually no requirement for the remainder of the molecule. Although this type of recognition was somewhat unexpected, it is fully consistent with the observed ability of a wide range of small acetylated compounds to partially inhibit the binding of L-ficolin to GlcNAc-Sepharose beads and to Streptococcus pneumoniae (Krarup et al., 2004).

\section{From the structure of the C1r catalytic domain to a $\mathrm{C} 1$ activation model}

The mechanism of action of $\mathrm{C} 1$, the multi-molecular complex that triggers the classical pathway of complement, has remained for many years a puzzling question. Although the details of this mechanism are largely still to be elucidated at the atomic level, the use of X-ray crystallography techniques has permitted significant advances in this respect, greatly improving our overall understanding of the complex (Gaboriaud et al., 2004). One of the most intriguing aspects of $\mathrm{C} 1$ function lies in the mechanisms that allow activation of its $\mathrm{C} 1 \mathrm{r}$ subunit, and in the nature of the signal that triggers this process when $\mathrm{C} 1$ binds to a target. To address these questions, the catalytic domain of $\mathrm{C} 1 \mathrm{r}$, encompassing the $\mathrm{CCP}_{1}$ and $\mathrm{CCP}_{2}$ modules and the $\mathrm{C}$-terminal serine protease (SP) domain, was trapped in the proenzyme state by means of a mutation at the Arg446-Ile447 cleavage site. Substitution of Gln for Arg446 prevents cleavage by the catalytic site of C1r, which shows a restricted specificity for arginyl and lysyl bonds (Lacroix et al., 2001). The three-dimensional structure of the domain was solved by X-ray crystallography to a resolution of $2.9 \AA$ (Budayova-Spano et al., 2002a), revealing a homodimeric head-to-tail assembly held together by non- 

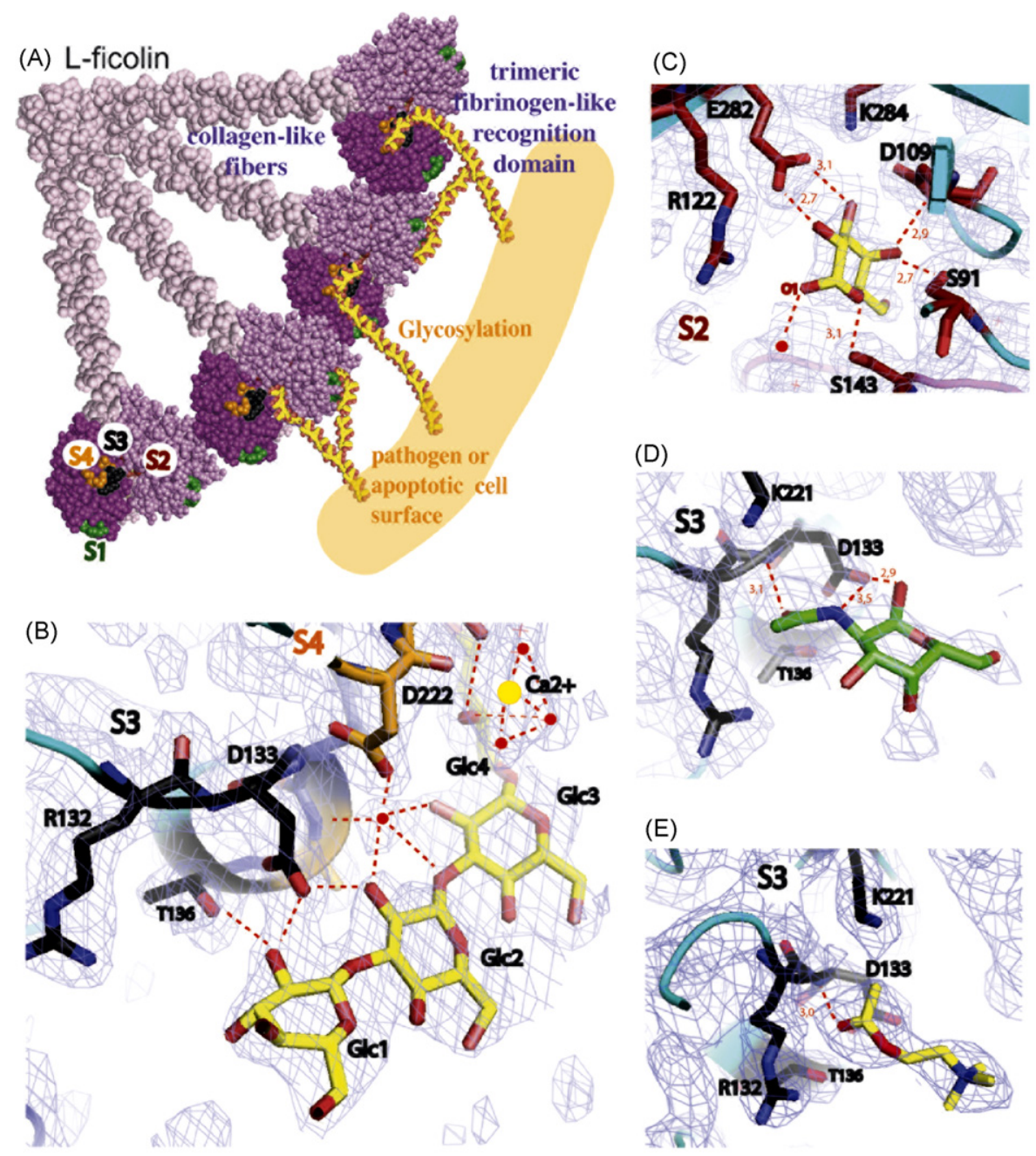

Fig. 1. The unpredicted binding sites S2-S4 discovered in L-ficolin. (A) Schematic overall drawing of the L-ficolin structure and recognition properties. The positions of the bindings sites S1-S4 are coloured and labelled in one recognition domain. (B) 1,3- $\beta$-D-glucan (light green), a marker of yeast surfaces, binds along S3 (black) and S4 (orange). (C) A galactose molecule (yellow) fits into S2 (red), with stabilizing interactions involving all its oxygens except O1. (D, E) Diverse small acetylated ligands can bind S3 (black) in a variety of orientations, as illustrated by GalNAc (dark green) and acetylcholine (yellow). Flexible acetylated carbohydrates (such as GalNAc) can adopt various orientations inside S3, hence their diffuse electron density map.

covalent interactions (including hydrogen bonds and van der Waals contacts) between the $\mathrm{CCP}_{1}$ module of one monomer and the SP domain of its counterpart (Fig. 2). That the C1r catalytic domain associates as a homodimer in solution has been demonstrated using various techniques (Villiers et al., 1985; Weiss et al., 1986; Lacroix et al., 2001). Likewise, the particular head-totail configuration seen in the structure is consistent with previous chemical cross-linking experiments and with the observation that deletion of the $\mathrm{CCP}_{1}$ module prevents dimer formation (Lacroix et al., 1997, 2001). It appears very likely, therefore, that this crystal structure is physiologically relevant and corresponds to a resting, thermodynamically stable conformation of the $\mathrm{C} 1 \mathrm{r}$ catalytic domain.

From a structural standpoint, an unexpected feature of the assembly is the presence of a large opening, with estimated dimensions of $30 \AA \times 13 \AA$, in the centre of the dimer (Fig. 2). At the functional level, it is interesting to note that the catalytic sites of the serine protease domains lie at either end of the dimer, facing away from the central opening. The mutated Gln446-
Ile447 sequence stretch, corresponding to the natural Arg-Ile cleavage site of each monomer, is located in a loop that protrudes from opposite corners of the dimer, approximately $90 \AA$ away from the catalytic site of the other monomer. Clearly, this configuration cannot account for $\mathrm{C} 1 \mathrm{r}$ self-activation, because this process requires cleavage of the susceptible Arg-Ile bond of each monomer by the catalytic residue Ser637 of its counterpart (Lacroix et al., 2001). Based on this requirement, it was postulated that $\mathrm{C} 1 \mathrm{r}$ activation within the $\mathrm{C} 1$ complex must take place through transient conformational states allowing the serine protease domain of one monomer to cleave its counterpart, and vice versa. Obviously, this process requires dissociation of the head-to-tail structure seen in the crystal, and therefore disruption of the non-covalent interaction between the $\mathrm{CCP}_{1}$ module and the SP domain (Fig. 2). This has led us to propose that the signal that causes this dissociation and hence triggers $\mathrm{C} 1 \mathrm{r}$ activation in $\mathrm{C} 1$ is a mechanical stress that is transmitted from the C1q collagen-like stems to the $\mathrm{C} 1 \mathrm{r}$ catalytic domain when $\mathrm{C} 1$ binds to an activator (Budayova-Spano et al., 2002a). This mech- 

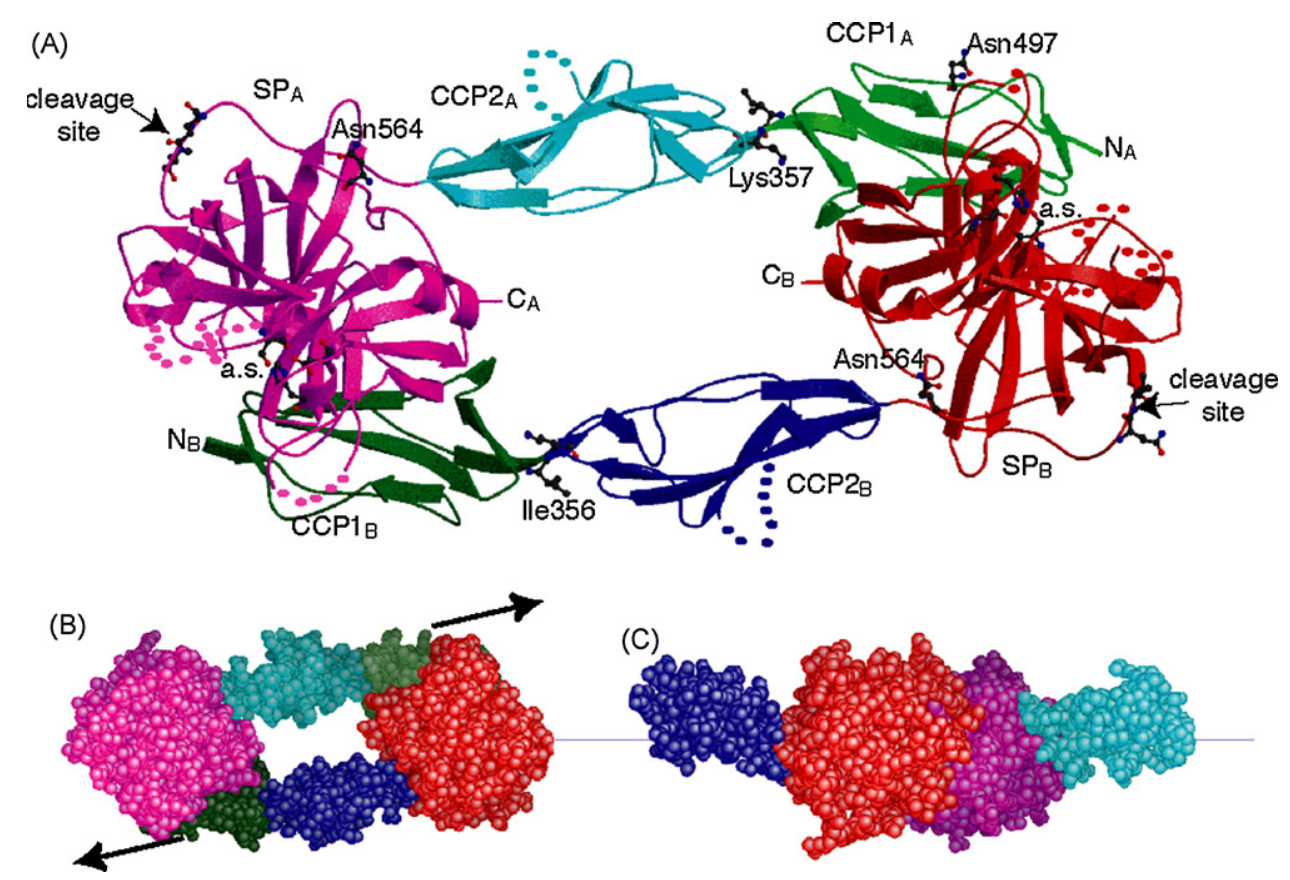

Fig. 2. Structure of the $\mathrm{C} 1 \mathrm{r}$ catalytic domain and its implications in the $\mathrm{C} 1$ activation mechanism. (A) Homodimeric structure of the zymogen $\mathrm{CCP}_{1}-\mathrm{CCP}_{2}-\mathrm{SP}$ fragment. The residues at the cleavage site and at the catalytic site (a.s.) are shown. $\mathrm{N}_{\mathrm{A}}, \mathrm{N}_{\mathrm{B}}$ and $\mathrm{C}_{\mathrm{A}}, \mathrm{C}_{\mathrm{B}}$ indicate the $\mathrm{N}$ - and $\mathrm{C}$-terminal ends of monomers $\mathrm{A}$ and $\mathrm{B}$. (B) Resting head-to-tail configuration of the $\mathrm{C} 1 \mathrm{r}$ catalytic domain. Arrows illustrate the tension required to achieve the transient conformational state (C) needed for activation of one SP domain by its counterpart.

anism is consistent with the presence of a semi-flexible hinge in $\mathrm{Clq}$ at the point where the collagen-like stems join to form the central stalk (Poon et al., 1983), and with the fact that each $\mathrm{C} 1 \mathrm{r}$ catalytic domain is connected to the $\mathrm{N}$-terminal interaction domain, which itself is bound to a collagen-like stem (Gregory et al., 2003). Thus, it is conceivable that multivalent binding of $\mathrm{C} 1 \mathrm{q}$ through its globular heads to a pattern of sites at the surface of a target will make some of the stems swing away from the centre of the complex, generating stress forces in the $\mathrm{Clr}$ catalytic domains that result in disruption of the $\mathrm{CCP}_{1}$ module-SP domain interface. The interaction between the two SP domains is obviously rendered possible by the presence of the large opening in the centre of the $\mathrm{C} 1 \mathrm{r}$ catalytic domain. It is also likely to be facilitated by intermodular flexibility in $\mathrm{C} 1 \mathrm{r}$, particularly at the $\mathrm{C} 1 \mathrm{r} / \mathrm{C} 1 \mathrm{~s}$, Uegf, Bmp1 (CUB) $)_{2}-\mathrm{CCP}_{1}$ and $\mathrm{CCP}_{1}-\mathrm{CCP}_{2}$ junctions and possibly also at the $\mathrm{CCP}_{2}-\mathrm{SP}$ domain interface, which shows restrained flexibility as revealed by a comparison of available X-ray structures (Budayova-Spano et al., 2002a,b).

Further insights into the $\mathrm{C} 1 \mathrm{r}$ activation mechanism have been provided by the structure of the zymogen and active forms of a shorter $\mathrm{CCP}_{2}-\mathrm{SP}$ fragment of C1r (Budayova-Spano et al., $2002 \mathrm{~b}$ ). Thus, the structure of the zymogen Ser637Ala mutant indicates that, like most other zymogens, the SP domain of C1r exhibits a high degree of flexibility, notably on either side of the Arg446-Ile447 cleavage site. Comparison of the zymogen and active structures reveals that multiple conformational changes, often of high amplitude, take place in the SP domain upon activation. Additional information relevant to $\mathrm{C} 1 \mathrm{r}$ self-activation may be drawn from the crystal contacts observed in the zymogen and active $\mathrm{CCP}_{2}-\mathrm{SP}$ structures (Budayova-Spano et al., 2002b). Thus, in the proenzyme Ser637Ala mutant, the SP domains inter- act with each other in a nearly symmetrical conformation that may represent an intermediate state of the activation process. As for the active molecules, they are packed in such a way that they form an enzyme-product-like complex, probably similar to the one occurring upon activation of one $\mathrm{C} 1 \mathrm{r}$ molecule by its counterpart (Fig. 2). Considered as a whole, the information provided by X-ray crystallography of the $\mathrm{C} 1 \mathrm{r}$ catalytic domain provides precise structural insights into the mechanisms that allow the whole $\mathrm{C} 1$ machinery to undergo activation (Gaboriaud et al., 2004).

\section{Serine proteases in complement activation}

Serine proteases of human complement are distinguished by their narrow substrate specificity and the unique mechanisms by which they are activated (Arlaud et al., 1998; Volanakis and Arlaud, 1998). With one exception out of eight, complement proteases are modular in composition and are proposed to undergo extensive structural rearrangement upon activation as parts of large multi-protein complexes (Arlaud et al., 1998; Volanakis and Arlaud, 1998). Factor D is the smallest in size of the complement proteases. It consists solely of a typical chymotrypsin-like serine protease domain (Volanakis and Narayana, 1996), while the other proteases are all endowed with additional structural modules. These modules are attached to the N-terminal ends of the respective serine protease domains. Some of these additional modules are specifically adapted for adhesion to cofactors, while others are responsible for restricting the enzymes to their inactive forms.

The single-domain factor $\mathrm{D}$, the essential enzyme for the activation of the alternative pathway, appears to be designed 


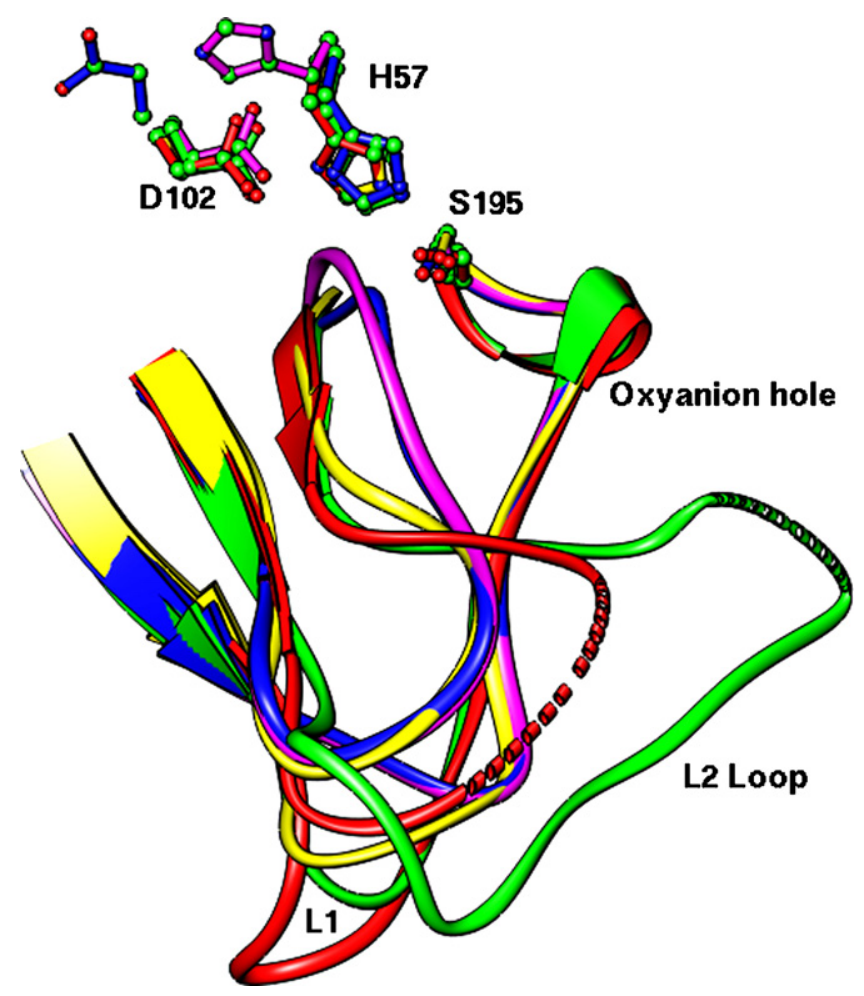

Fig. 3. Superposition of the S1 pockets of serine proteases factor B (red), C2 (green), factor D (molecule A in blue, molecule B in magenta), and trypsin (yellow). The catalytic triad is shown with chymotrypsinogen numbering.

specifically for the activation of another complement serine protease factor $\mathrm{B}$, a five-domain enzyme, but only does so when factor $\mathrm{B}$ is bound to $\mathrm{C} 3 \mathrm{~b}$ and in the presence of $\mathrm{Mg}^{2+}$. Unlike most of the serine proteases, no zymogen form of factor D exists and no known serpin-like inhibitor for this enzyme has been identified in the circulation (Volanakis and Narayana, 1996). Activation and regulation of this unique enzyme remained a mystery for enzymologists until structural biologists were able to apply a combination of X-ray crystallography, sitedirected mutagenesis and measurements of enzyme kinetics to the problem. This work revealed a correlation between the unique primary sequence substitutions in and around the substrate binding pocket and its narrow substrate specificity. The structural correlates include (i) the atypical catalytic triad, (ii) a single tight $\beta$-turn 'oxyanion hole', (iii) the atypical conformation of the loop that defines the secondary substrate binding pockets $\mathrm{S} 2, \mathrm{~S} 3 . .$. , etc. and provides backbone $\mathrm{H}$-bonds to the bound substrate, and (iv) the blocked primary substrate binding $\mathrm{S} 1$ pocket. The circulating factor $\mathrm{D}$ has its $\mathrm{N}$-terminus tucked in, held firmly in position by a salt bridge to the acidic residue adjacent to the catalytic Ser195 residue like any other activated serine protease. Yet circulating factor D exhibits no enzymatic activity towards its substrate or towards substrate-like small peptides. This was explained by the presence of an atypical catalytic triad in which the catalytic His residue exhibits an atypical (for serine proteases) trans-conformation (Fig. 3). Such a conformation is possible mainly because of replacement of a highly conserved hydrophobic residue that forces the catalytic His to adopt a cis-conformation in all other serine proteases, by a Ser residue. Similarly, replacement by a Ser residue of a conserved hydrophobic residue, which is a member of a hydrophobic cluster stabilizing the conformation of the 'secondary substrate binding loop', facilitates the atypical elevation (with respect to the body of the protein) of this loop. The elevated position of this loop is aided by additional, unique, substitution of a conserved Ser with a Thr, which also contributes to the trans-conformation observed for the catalytic His residue. Serine proteases that are specific to substrates with an Arg residue at the P1 position provide a negative charge at the bottom of the S1 pocket that is essential for holding the P1-Arg so as to place the scissile bond in the appropriate orientation. In factor $\mathrm{D}$, such a negative charge is occluded from the approaching substrate by a salt bridge formed between Arg and Asp residues present at the bottom of the S1 pocket. Site-directed mutagenesis combined with enzyme kinetic studies validated the proposed roles of these unique substitutions in and around the S1 pocket. Hence, factor $\mathrm{D}$ activation is regulated by three unique structural features, a result of three single amino acid residue substitutions that help to eliminate both the need for enzymatic $\mathrm{N}$-terminal activation of a zymogen to form the mature enzyme and the need for a protein inhibitor that can effectively remove the enzyme from the circulation as a regulatory step. It has been proposed that factor $\mathrm{D}$ circulating as an inactive 'resting enzyme' is activated by its substrate C3b-bound factor B. The substrate activates factor D by reorienting its catalytic triad and rearranging its $S 1$ pocket. Subsequently, factor $\mathrm{B}$ gets cleaved into $\mathrm{Ba}$ and $\mathrm{C} 3 \mathrm{~b}$-bound $\mathrm{Bb}$. Then factor D reverts back to the 'resting enzyme' status in the circulation. This unique method of proteolysis has been termed 'substrate-induced' catalysis (Volanakis and Narayana, 1996), in which the essential activation and regulation of factor $\mathrm{D}$ are carried out by subtle and reversible conformational changes that are possible mainly due to three amino acid substitutions at critical positions.

Factor $\mathrm{B}$ and $\mathrm{C} 2$ are two homologous, multi-domain enzymes that are nearly completely inactive as individual proteins. They contribute their catalytic domains to the $\mathrm{C} 3$-convertases of the alternative pathway (C3b.Bb) and the classical pathway (C4b.C2a), respectively. Protein C3 is the only known substrate for these enzymes and is cleaved only when the catalytic fragments of factor $\mathrm{B}(\mathrm{Bb})$ and $\mathrm{C} 2(\mathrm{C} 2 \mathrm{a})$ are associated with cofactors C3b and C4b, respectively (Arlaud et al., 1998). Each of these enzymes carries a P1-Arg-specific chymotrypsin-like serine protease domain at its $\mathrm{C}$-terminal end. Activation of these serine proteases must occur through different mechanisms compared to other single-domain serine proteases, since factor B and $\mathrm{C} 2$ do not have free $\mathrm{N}$-termini. The proteolytic domains of factor B and C2 are linked to highly conserved von Willebrand factor type A (vWFA) domains that carry metal ion-dependent adhesion site (MIDAS) motifs. Each of these proteases also carries three $\mathrm{CCP}$ modules at its $\mathrm{N}$-terminal end. The recent crystal structure of full-length factor $\mathrm{B}$ revealed the position of the $\mathrm{CCP}$ modules to be on one side of the molecule, covering the interface between the serine protease and vWFA domains (Milder et al., 2007). For a long time, it was assumed that cofactors $\mathrm{C} 3 \mathrm{~b}$ and $\mathrm{C} 4 \mathrm{~b}$, by associating through the MIDAS motifs present in the vWFA domains of factor $\mathrm{B}$ and $\mathrm{C} 2$, respectively, were 
responsible for activation of these enzymes. There was also a suggestion that the catalytic machinery of these enzymes is occluded by their own CCP modules and that the loss of these modules precedes activation.

However, the crystal structures of factor B (Milder et al., 2007; Ponnuraj et al., 2004), C2 (Krishnan et al., 2007; Milder et al., 2006) and their individual domains (Bhattacharya et al., 2004; Xu et al., 2000), in combination with site-directed mutagenesis and enzyme kinetic studies, revealed some interesting structural details that correlate with both the narrow substrate specificity and the unique activating mechanisms of these enzymes. These findings revealed that the four essential structural features (Fig. 3) that are responsible for the efficient function of the serine proteases (namely, the catalytic triad, the 'oxyanion hole', the substrate-specific S1 pocket and the loops bordering the pockets) are in the right orientations and conformations with the exception of the 'oxyanion hole' that dictates enzymatic efficiency. In both factor B and C2, this region displays a single-turn $3_{10}$ helix instead of the usual tight $\beta$-turn. Another important revelation from these structural studies is that the MIDAS-induced conformational changes apparently cannot extend beyond the linker joining the serine protease and vWFA domains. It follows that these changes merely displace the linker that connects the C-terminal CCP domain to the vWFA domain. This displacement facilitates the cleavage of $\mathrm{Ba}$ from $\mathrm{C} 3 \mathrm{~b}$-bound factor $\mathrm{B}$ and $\mathrm{C} 2 \mathrm{~b}$ from $\mathrm{C} 4 \mathrm{~b}$-bound $\mathrm{C} 2$ by factor $\mathrm{D}$ and $\mathrm{C} 1 \mathrm{~s}$, respectively.

Thus, 'substrate-induced catalysis' seems to be the new paradigm for the activation of complement serine proteases factor $\mathrm{D}$, factor $\mathrm{B}$, and $\mathrm{C} 2$. The cofactor-induced conformational changes in factor B and C2 do not activate their proteolytic apparatuses, and binding to their respective cofactor merely helps to dislodge their N-terminal 'restrictive' CCP domain. We speculate that the removal of the N-terminal CCP domain from its position in the proenzyme might facilitate the approach of, and free-up space for, substrate $\mathrm{C} 3$ binding to the respective enzymes. In other words, once the N-terminal CCP has been removed, the relative orientation between the serine protease and vWFA domains (different between factor $\mathrm{B}$ and $\mathrm{Bb}$ (Milder et al., 2007)) might be stabilized by the bound cofactors, which can also act as 'platforms' for positioning the $\mathrm{C} 3$ substrate in a suitable orientation for activation of the 'disordered' active sites in factor $\mathrm{B}$ and $\mathrm{C} 2$. However, we do not know much about the possible conformational changes $\mathrm{C} 3, \mathrm{C} 3 \mathrm{~b}$, and $\mathrm{C} 4 \mathrm{~b}$ might undergo during the binding, cleavage, and generation of $\mathrm{C} 3 \mathrm{~b}$. Visualizing these changes is the next goal for structural biologists.

\section{Crystal structures of $\mathrm{C3}$ and its fragments}

In 2005, Janssen et al. presented the complete threedimensional structures of the central complement component $\mathrm{C} 3$ and of its proteolytic fragment C3c (Janssen et al., 2005). These studies revealed a remarkable structure of this 1641 amino-acid long protein molecule featuring an intricate domain arrangement, which pointed to a possible evolution of this type of host-defence molecule. These data on intact $\mathrm{C} 3$, together with the previously available structure of a $\mathrm{C} 3 \mathrm{~d}$ construct produced in E. coli (Nagar et al., 1998), afforded insights into the molecular mechanisms of thioester protection and activation, which are essential for the covalent attachment of $\mathrm{C} 3 \mathrm{~b}$ to its target surfaces. These structural findings for human C3 were confirmed by the subsequent report of the structure of bovine $\mathrm{C} 3$ by Fredslund et al. (2006). Recently, these structures were complemented by the structures of the activated $\mathrm{C} 3 \mathrm{~b}$ molecule (Janssen et al., 2006) and of C3b in complex with the cell-surface receptor and inhibitor, CRIg (Wiesmann et al., 2006). In addition, Nishida et al. (2006) provided a comprehensive view of all major structural conformations of C3 and its fragments by electron microscopy. This wealth of structural data provides unprecedented opportunities to study the molecular mechanisms of this central molecule of the complement system.

\subsection{Domain organization of $C 3$}

The structure determination of human $\mathrm{C} 3$ resolved the intricate domain organization of this large protein molecule for the first time (Janssen et al., 2005). Previously, only limited information was available on the domain organization of proteins from the C3/ 2 2-macroglobulin family. Four structural elements of C3 or homologous proteins were known a priori: (i) the anaphylatoxin domain C3a (Huber et al., 1980) and C5a (Zuiderweg et al., 1989), (ii) the fragment $\mathrm{C} 3 \mathrm{~d}$ and its homologue $\mathrm{C} 4 \mathrm{~d}$, which correspond to the thioester-containing domain of C3 and C4 (Nagar et al., 1998; van den Elsen et al., 2002; Zanotti et al., 2000), as well as C3d in complex with the CCP1-2 construct of complement receptor 2 (CR2) (Szakonyi et al., 2001), (iii) the receptor-binding domain (RBD) of $\alpha 2$-macroglobulin $(\alpha 2 \mathrm{M})$ (Jenner et al., 1998), and (iv) the C-terminal C345c domain of C5 (Bramham et al., 2005). For the remainder ( $60 \%)$ of the molecule, most sequence databases listed two large domains, denoted $\alpha 2 \mathrm{M} \_\mathrm{N}$ for the $\mathrm{N}$-terminal part and $\alpha 2 \mathrm{M}$ for the $\mathrm{C}$ terminal part (the latter included the region corresponding to the RBD domain in $\alpha 2 \mathrm{M})$.

The crystal structures of C3 (Janssen et al., 2005; Fredslund et al., 2006) revealed that the two separate $\beta$ (res. 1-645) and $\alpha$ (res. 650-1641) chains form 13 domains. The core of the protein is formed by eight homologous domains, which are referred to as macroglobulin (MG) domains. These domains are formed by two stacked $\beta$-sheets with an overall topology that is also observed for fibronectin type III (FN3) domains. Structurally, these eight domains are arranged in ring-like fashion of $1 \frac{1}{2}$ turns (domains MG1-6) capped by two domains (MG7 and MG8). Onto this core, other domains are crafted. First, a large insert (res. 578-745) forms the linker (LNK) domain and the anaphylatoxin (ANA) domain. This insert includes the processing site 646-RRRR-649, which is removed before secretion, resulting in the mature molecule consisting of two chains, $\beta$ and $\alpha$. A remarkable structural feature of this insert is that it loops through the central hole of the MG1-6 ring. Second, another large insert, res. 912-1330, forms a CUB domain and the thioester-containing domain (TED). Third and finally, a C345c domain forms a Cterminal extension onto the MG8 domain. Remarkably, these inserts and the extension carry regions that are critical for the functioning of $\mathrm{C} 3$. 


\subsection{The thioester of $\mathrm{C} 3$}

A critical feature of the $\mathrm{C} 3$ molecule is the covalent surface attachment through its reactive thioester moiety. This thioester is formed by Cys-988 and Gln-991 located on the convex side of the TED domain, as first shown by the structure of C3d (Nagar et al., 1998). In the two structures of C3, the thioester moiety is intact and protected from the surrounding solvent. The packing of TED onto the MG8 domain yields a hydrophobic/aromatic cap around the thioester that limits access by small reactive groups. Moreover, a study by Law and Dodds (1997) showed that reactivity towards amino and hydroxyl nucleophiles depends on two different reaction states of the thioester, these are a thioester that is most reactive towards amino nucleophiles and an acylimidazole state that is most reactive towards hydroxyl nucleophiles. The structures of intact $\mathrm{C} 3$ clearly show the thioester arrangement that is most reactive towards amino nucleophiles. The structure of C3d (Nagar et al., 1998) and correspondingly the structures of the TED domain in C3b (Janssen et al., 2006; Wiesmann et al., 2006), however, are markedly different in the arrangement around the thioester residues. Consistent with the model proposed by Law and Dodds (1997), His-1104 and Glu-1106 align with Gln-991 and Cys-988 (mutated to Ala in the C3d construct used by Nagar et al., 1998) to form an acylimidazole intermediate that is reactive towards hydroxyls. The rearrangement involves loop movements over a $10-\AA$ distance. These conformational changes are blocked in the structure of native C3 by the presence of MG8. Thus, these data indicate that thioester activation in $\mathrm{C} 3$ is inhibited by a hydrophobic/aromatic cap limiting access of small nucleophiles and by preventing loop rearrangements that lead to the acylimidazole intermediate which is reactive towards hydroxyls and water.

\subsection{Conformational changes involved in C3 activation}

The recent structures of C3b (Janssen et al., 2006) and C3b in complex with CRIg (Wiesmann et al., 2006) revealed that the molecule undergoes marked conformational changes with shifts up to $\sim 95 \AA$ in distance upon activation of $\mathrm{C} 3$. Activation of $\mathrm{C} 3$ into $\mathrm{C} 3 \mathrm{~b}$ occurs through proteolytic removal of the ANA domain producing the small fragment, anaphylatoxin $\mathrm{C} 3 \mathrm{a}$ and the large fragment $\mathrm{C} 3 \mathrm{~b}$. In native $\mathrm{C} 3$, ANA interacts with both MG8 and MG3 of the relatively stable MG ring. Most likely, these interactions stabilize the position of MG8. Thereby, ANA stabilizes indirectly the MG8-TED interaction, which is crucial for preserving native $\mathrm{C} 3$. Upon removal of ANA, the MG7 and MG8 domains swivel and the MG8-TED interface are lost and the CUB and TED domains (which are sequentially in between the MG7 and MG8 domains) swing out. In both structures of C3b (Janssen et al., 2006; Wiesmann et al., 2006), the TED domain is located next to the MG1 domain, far away from its nested position in native $\mathrm{C} 3$ and with its thioester fully exposed (see Fig. 4). Concomitantly, the new $\mathrm{N}$-terminus of the $\alpha$-chain, denoted $\alpha$ '-chain, markedly relocates from the ANA position close to MG8 through the central hole of the MG ring to the opposite side on MG7. These striking rearrangements are likely of functional importance. The $\mathrm{N}$-terminus carries several acidic residues that have been shown to be important for binding factor $\mathrm{B}$ in the formation of the convertase complex (Taniguchi-Sidle and Isenman, 1994); these residues are occluded by ANA in native $\mathrm{C} 3$ and exposed on the opposite of the molecule in $\mathrm{C} 3 \mathrm{~b}$. Moreover, the $\alpha^{\prime}-\mathrm{N}$ terminus and subsequent residues on MG6 harbor binding sites for regulators factor $\mathrm{H}$ and complement receptor type 1 (CR1) (Becherer et al., 1992; Fishelson, 1991; Lambris et al., 1996; Oran and Isenman, 1999; Taniguchi-Sidle and Isenman, 1994). Relocation of the MG7-CUB-TED-MG8 domains, a conformational switch of the anchor region and a rotation of the $\mathrm{C} 345 \mathrm{c}$ domain result in a markedly different constellation of the $\alpha$-chain onto the stable platform formed by the MG ring. This rearrangement of domains opens up a variety of binding sites for factor B and various regulators of complement activity (see, e.g., Janssen et al., 2006 for a mapping of binding sites onto the structure of $\mathrm{C} 3 \mathrm{~b}$ ).

Thus, these studies of $\mathrm{C} 3$ have provided unprecedented insights into structure and function of this central molecule of the complement system. Clearly, understanding the molecular mechanisms of convertase formation through binding and cleavage of factor $\mathrm{B}$ and the convertase dissociation and decay through activity of regulators and factor I requires structural data of C3b in complex with its interacting proteins. Most likely, this type of structural data will provide us with insights into the molecular mechanisms of complement activation and regulation, which will be instrumental in developing new drugs to fight complement-mediated diseases.

\section{Structure-function relationships in the regulators of complement activation}

The regulators of complement activation (RCA) are a family of glycoproteins that act upon the bimolecular and trimolecular C3- and C5-convertases (Kirkitadze and Barlow, 2001). Factor $\mathrm{H}$ and $\mathrm{C} 4 \mathrm{~b}$-binding protein $(\mathrm{C} 4 \mathrm{BP})$ are soluble, while membrane cofactor protein (MCP, CD46), decay accelerating factor (DAF, CD55) and CR1 (CD35) are expressed on the cell surface. This group of regulators have the aggregate effect of inhibiting formation of the C3- and C5-convertases, markedly shortening the life-span of existing convertase complexes, and facilitating proteolytic destruction of $\mathrm{C} 3 \mathrm{~b}$ and $\mathrm{C} 4 \mathrm{~b}$ by factor $\mathrm{I}$. In these ways, they restrain complement-mediated inflammation and prevent complement amplification on the surfaces of host cells and in extracellular matrix. Yet they permit a complement response to amplify and proceed unchecked on non-host material. Defective complement regulation contributes to symptoms of numerous diseases. Anti-complement therapeutics could be designed on the basis of these natural regulators (Brook et al., 2005; Morgan and Harris, 2003) given a better understanding of their structure-function relationships.

Each RCA member has a distinct functional profile, but all rely on possession of a single domain or module type to carry out their tasks (Reid and Day, 1989; Soares and Barlow, 2005). This $\sim 7 \mathrm{kDa}(\sim 60$ aa) module has been termed short consensus repeat (SCR), sushi domain, or CCP and is identifiable from its consensus sequence that includes a tryptophan and four cysteine residues (Soares and Barlow, 2005). From 4 to 30 CCPs are pre- 
(A)

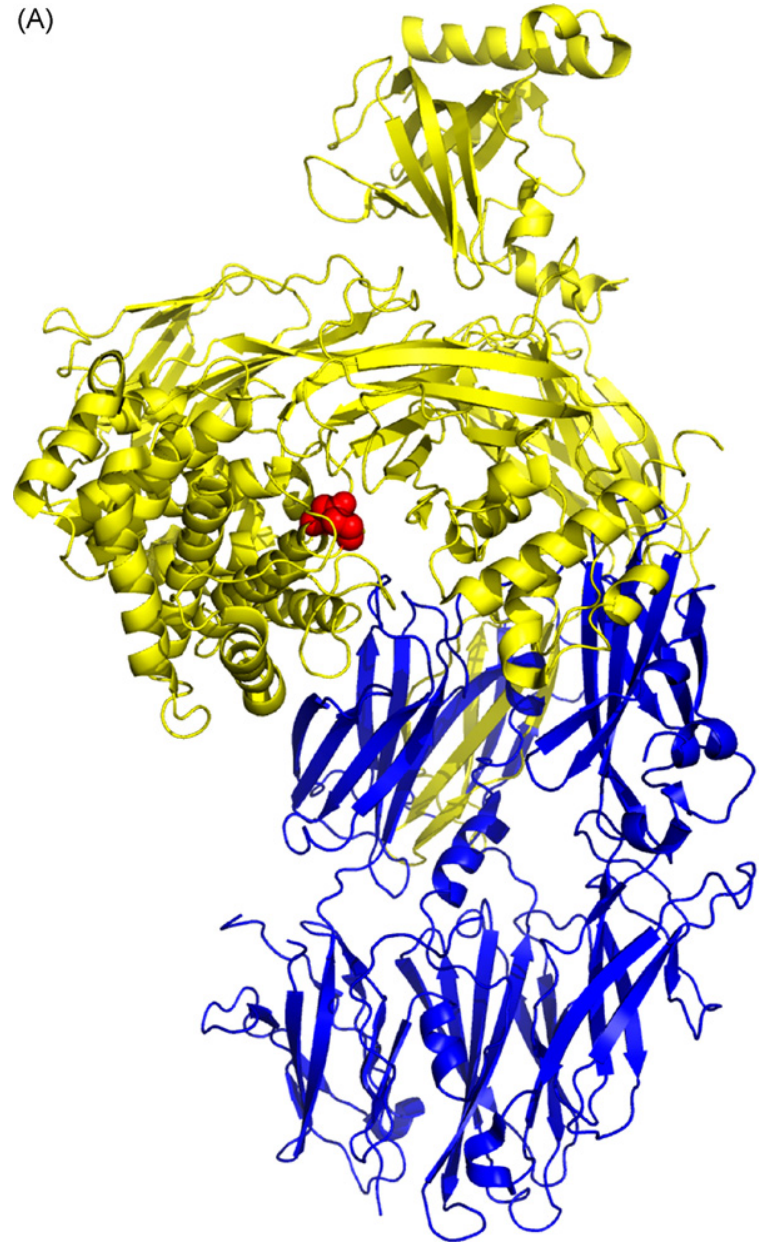

(B)

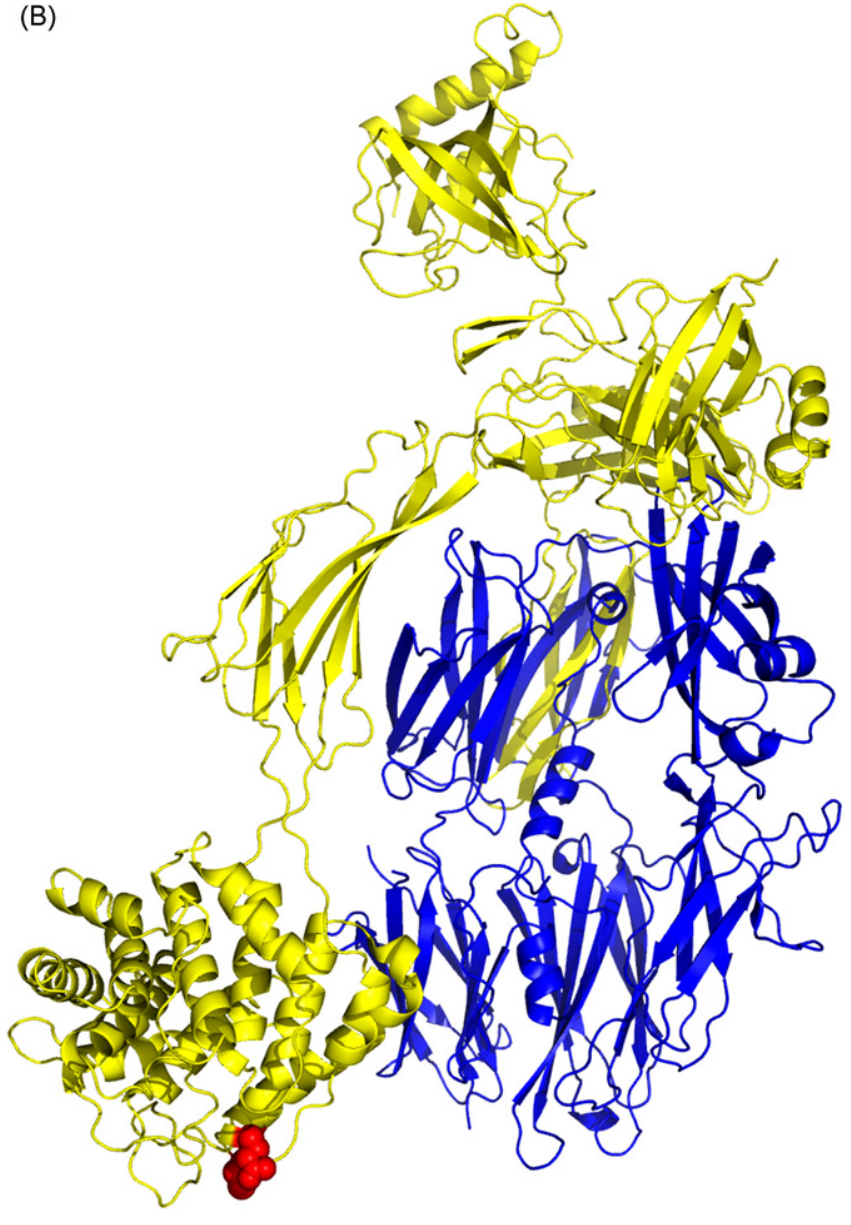

Fig. 4. Cartoon representation of C3 (A) and C3b (B). Blue indicates the $\beta$-chain and yellow indicates the $\alpha$-chain. The red spheres indicate the position of the thioester moiety. PDB files used are 2A73 and 2I07.

dicted in each of the most common RCA allotypes. For example, the principal, soluble RCA controlling the alternative pathway, factor $\mathrm{H}$ (Fig. 5), is composed entirely from 20 tandem CCPs (Ripoche et al., 1986) of between 51 and 62 residues, linked by sequences of between three and eight residues (a seven-module splice variant, factor H-like 1 also has complement regulatory properties (Zipfel et al., 1999)). Examples of CCPs are additionally present in complement proteins other than RCAs (e.g. $\mathrm{C} 1 \mathrm{r}$ and $\mathrm{C} 1 \mathrm{~s}$ (see above), $\mathrm{C} 6$ and $\mathrm{C} 7$, as well as $\mathrm{C} 2$ and factor B (see above)), and in at least 50 further human proteins (http://smart.embl-heidelberg.de/).

Despite their similarity to each other, the various CCPs within an RCA perform different tasks. For example, factor H's Nterminal four CCPs are together sufficient to accelerate the decay of convertases and act as a factor I cofactor (Gordon et al., 1995; Sharma and Pangburn, 1996). The remaining modules are primarily concerned with ensuring factor $\mathrm{H}$ discriminates between healthy host tissue (where it acts protectively) and waste or foreign material (where its complement regulatory activities are not manifested). In all, factor $\mathrm{H}$ has three distinct binding sites for three discrete regions of C3b (Jokiranta et al., 2000; Sharma and Pangburn, 1996), and three probably separate binding sites for sialic acid/glycosaminoglycans (GAGs) (Meri and Pangburn,
1994; Ormsby et al., 2006) (Fig. 5). The latter provide the means whereby factor $\mathrm{H}$ recognises and binds selectively to the surfaces that it is designed to protect (Pangburn, 2000).

From the structural biologist's perspective, factor $\mathrm{H}$ and the other RCAs represent an enigma; how does a single type of module - the CCP in this case - perform the diverse range of duties required to achieve the functional sophistication of the parent proteins? In this respect, the RCAs are simple models for 1000s of multiple-module human proteins that are constructed by stringing together various combinations of module-types selected from a limited pool (Bork et al., 1996). Such proteins dominate the extracellular environment but are under-represented in the database of solved structures due to the inherent difficulties associated with their generally large size and potentially flexible nature. In the cases of factor $\mathrm{H}$ (Aslam and Perkins, 2001) and CR2 (Gilbert et al., 2006), small-angle X-ray scattering and sedimentation studies have shed light on overall, low-resolution structures. For example, these methods provide support for a folded-back conformation of factor H (Fig. 5), consistent with the preponderance of smaller CCPs and longer linkers in its central region. Much of the high-resolution structural work to date has involved effectively breaking up the RCAs into more tractable fragments. 


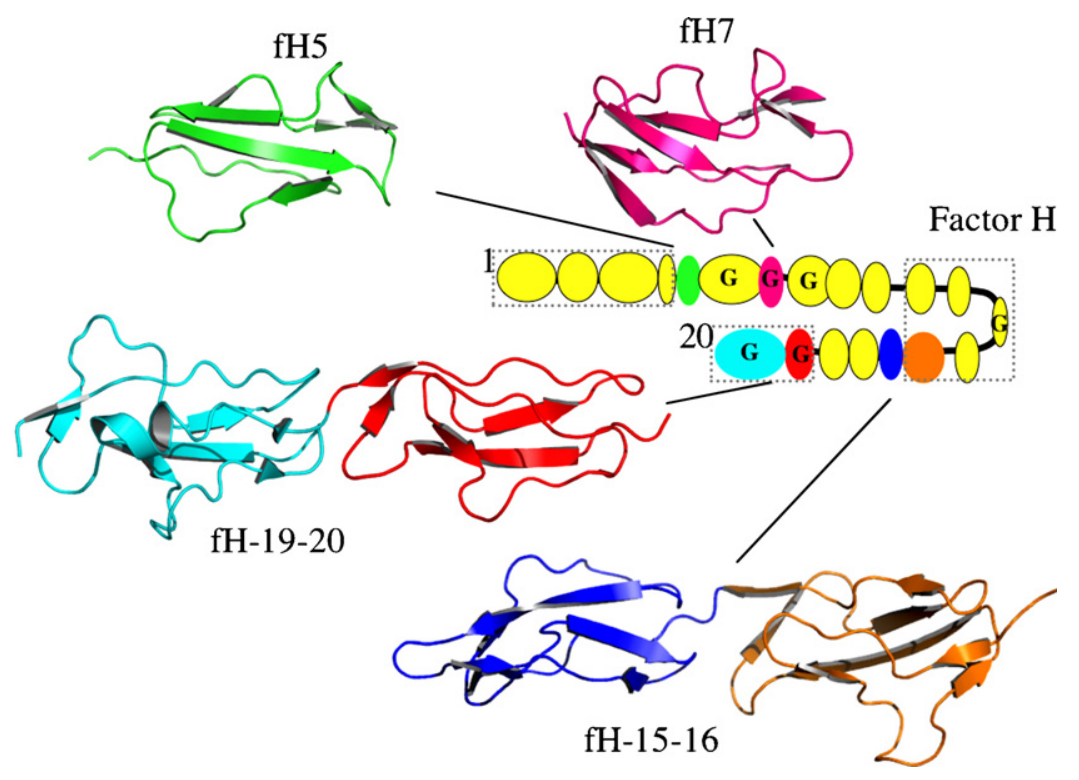

Fig. 5. Three-dimensional structures of CCPs from factor H. Factor H is drawn as a series of ovals representing its 20 CCPs. The CCPs of known structure (see Table 1 for details) are colour coded. The variation in module size (51-62 aas) and linker-length (3-8 aas) are exaggerated to highlight predominance of smaller modules and longer linkers in central region where the molecule might fold back on itself. Grey, dotted boxes indicate CCPs involved in binding to $\mathrm{C} 3 \mathrm{~b}$; $\mathrm{G}=\mathrm{CCP}$ implicated in GAG binding (there is controversy as to whether the central GAG-recognition site is CCP 13 as shown or CCP 9); for references see text.

Three-dimensional structures of $\sim 40$ CCPs have been solved (Table 1), including $\sim 19$ from the human RCA family. Most of the remaining RCA CCP structures have been modelled by homology (Soares et al., 2005). Structures of individual modules and of strings of CCPs, or structures of CCPs complexed with binding partners, are available. For example, for factor $\mathrm{H}$, early work generated the NMR-derived solution structure of individual, recombinant, CCP16 (i.e. fH-16) (Barlow et al., 1991; Norman et al., 1991) followed by fH-5 (Barlow et al., 1992) and the double module fH-15-16 (Barlow et al., 1993). These afforded the first insights into RCA structures (Fig. 5), revealing a $\sim 1.5 \mathrm{~nm} \times \sim 4 \mathrm{~nm}$ prolate, $\beta$-strand-rich, module with a 1-3, 2-4 disulphide pattern. Amino- and C-termini occupy opposite ends of the long axis, and this early work revealed the extended, end-to-end, arrangement between adjacent modules also observed in most subsequently solved structures of CCPs, including all four modules of DAF (Lukacik et al., 2004; Uhrinova et al., 2003) and vaccinia virus complement control protein (VCP, a viral mimic of the mammalian RCAs) (Murthy et al., 2001), three modules (out of a total of 30) in CR1 (CCPs 15-17) (Smith et al., 2002) and the N-terminal module pair of both MCP (which has four CCPs) (Casasnovas et al., 1999) and C4BP $\alpha$-chain (with eight CCPs) (Jenkins et al., 2005). A very notable exception to this rule is provided by the $\mathrm{N}$-terminal pair of CCPs (out of a total of 15 or 16) in complement receptor type 2 (CR2, CD21) (Szakonyi et al., 2001) as studied in complex with the CR2 ligand, C3d, by X-ray crystallography; these two CCPs are joined by an eight-residue linker and adopt an antiparallel side-by-side arrangement burying $1400 \AA^{2}$. A further important exception is the CCPs 2-3 pair of factor B (Milder et al., 2007, see above), which are connected by only a five-residue linker yet fold back upon and embrace one another, burying $1340 \AA^{2}$ in the X-ray-derived structure. A so-far unique, but intriguing, strand-swapped pair of CCP modules was revealed in the crystal structure of the IL-2 receptor (Rickert et al., 2005).

Recently, much attention has focussed on fH-19-20, since this region carries many mutations linked to the rare kidney disease atypical haemolytic uremic syndrome (Rodriguez de Cordoba et al., 2004; Warwicker et al., 1998), culminating in both X-ray- and NMR-derived structures (Fig. 5) appearing almost simultaneously (Herbert et al., 2006; Jokiranta et al., 2006). A patch of fH-19-20 residues implicated by chemical shift perturbation assays in binding to a model glycosaminoglycan (a fully sulphated tetrasaccharide fragment of heparin) coincided with residues that are mutated in the factor $\mathrm{H}$ of some patients suffering from aHUS (Herbert et al., 2006). In other studies, this region (the $\mathrm{C}$-terminal pair of $\mathrm{CCPs}$ ) of factor $\mathrm{H}$ was shown to be predominant in self versus non-self-discrimination (Ferreira et al., 2006). Thus, a disease model in which dysfunctional factor $\mathrm{H}$ fails to fully protect the GAG-rich layers of the glomerular basement membrane in aHUS patients was supported. Given our current lack of knowledge of the specific GAGs recognised by fH-19-20 in a physiological setting, experimental demonstration of the functionally critical nature of disease-linked factor $\mathrm{H}$ mutations - e.g. by the more traditional route of mutagenesis and binding assay - is problematic. This difficulty highlights the unique value of the structural approach. Nonetheless, a question mark remains over the above interpretation due to the putative binding site in 19,20 for $\mathrm{C} 3 \mathrm{~b} / \mathrm{C} 3 \mathrm{~d}$ and the physiological relevance of its partial disruption by aHUS-linked mutations (Jokiranta et al., 2006).

A SNP in fH-7 was linked to the eye disease, age-related macular degeneration (AMD) (Hageman et al., 2005), triggering structural studies of individual fH-7 (Fig. 5) by NMR (Herbert et al., 2007), and subsequently a crystal structure of the triple module fH-6-8 (Susan Lea, personal communication). A com- 
Table 1

CCPs of known structure ${ }^{\mathrm{a}}$

\begin{tabular}{|c|c|c|c|}
\hline $\mathrm{CCP}$-containing protein & Accession no. & PDB code(s) & Modules solved \\
\hline Complement receptor 1 (CD35) & P17927 & $1 \mathrm{GKN}^{\mathrm{NMR}} 15,16,1 \mathrm{GKG}^{\mathrm{NMR}} 16,17,1 \mathrm{PPQ}^{\mathrm{NMR}} 16$ & $15,16,17$ (of 30$)$ \\
\hline Complement receptor $2(\mathrm{CD} 21)$ & P20023 & $1 \mathrm{GHQ}^{\mathrm{XR}} 1,2,1 \mathrm{LY} 2^{\mathrm{XR}} 1,2^{\mathrm{b}}$ & $1,2$ (of 15 or 16$)$ \\
\hline Decay accelerating factor (CD55) & P78361 & $\begin{array}{l}1 \mathrm{H} 03^{\mathrm{XR}} 3,4,1 \mathrm{H} 4^{\mathrm{XR}} 3,4,1 \mathrm{H} 2 \mathrm{P}^{\mathrm{XR}} 3,4, \\
1 \mathrm{H} 2 \mathrm{Q}^{\mathrm{XR}} 3,4,1 \mathrm{UOT}^{\mathrm{XR}} 3,4, \\
1 \mathrm{OJV}^{\mathrm{XR}} 1-4,1 \mathrm{OJW}^{\mathrm{XR}} 1-4,1 \mathrm{OJY}^{\mathrm{XR}} 1-4, \\
1 \mathrm{OK}^{\mathrm{XR}} 1-4,1 \mathrm{OK} 2^{\mathrm{XR}} 1-4,1 \mathrm{OK} 3^{\mathrm{XR}} 1-4,1 \mathrm{OK} 9^{\mathrm{XR}} 1-4, \\
1 \mathrm{NWV}^{\mathrm{NMR}} 2,3\end{array}$ & $1,2,3,4$ (of 4$)$ \\
\hline C4b-binding protein $\alpha$-chain & P04003 & $2 \mathrm{~A} 55^{\mathrm{NMR}} 1,2$ & $1,2$ (of 8$)$ \\
\hline Vaccinia virus complement control protein $(\mathrm{VCP})$ & P10998 & $\begin{array}{l}1 \mathrm{G} 40^{\mathrm{XR}} 1-4,1 \mathrm{G} 44^{\mathrm{XR}} 1-4, \\
1 \mathrm{VVC}^{\mathrm{NMR}} 3,4,1 \mathrm{VVD}^{\mathrm{NMR}} 3,4,1 \mathrm{VVE}^{\mathrm{NMR}} 3,4, \\
1 \mathrm{E}^{\mathrm{NMR}} 2,3, \\
1 \mathrm{RID}^{\mathrm{XR}} 1-4^{\mathrm{e}}, 1 \mathrm{Y}^{\mathrm{N}} \mathrm{E}^{\mathrm{XR}} 1-4^{\mathrm{f}}\end{array}$ & $1,2,3,4$ (of 4$)$ \\
\hline MASP-2 & O00187 & $1 \mathrm{Q} 3 \mathrm{X}^{\mathrm{XR}} 2^{\mathrm{h}}, 1 \mathrm{ZJK}^{\mathrm{XR}} 1,2^{\mathrm{h}}$ & $1,2($ of 2$)$ \\
\hline Apolipoprotein H (beta2-GPI) & P02749 & $1 \mathrm{C} 1 \mathrm{Z}^{\mathrm{XR}} 1-5,1 \mathrm{QUB}{ }^{\mathrm{XR}} 1-5$ & $1,2,3,4,5(\text { of } 5)^{\mathrm{i}}$ \\
\hline GABA-B receptor $1 \mathrm{a}^{\mathrm{j}}$ & Q9Z0U4 & $\begin{array}{l}1 \mathrm{SS}^{\mathrm{NMR}} 2 \text { (cis X-Pro form), } 1 \mathrm{SRZ}^{\mathrm{NMR}} 2 \text { (trans X-Pro } \\
\text { form) }\end{array}$ & $2(\text { of } 2)^{\mathrm{k}}$ \\
\hline Corticotrophin releasing factor receptor $2 \beta^{1}$ & Q60748 & $1 \mathrm{U} 34^{\mathrm{NMR}} 1,2 \mathrm{JNC} \mathrm{CMR}^{\mathrm{NM}}, 2 \mathrm{JND}^{\mathrm{NMR}} 1^{\mathrm{m}}$ & $1(\text { of } 1)^{\mathrm{n}}$ \\
\hline Interleukin-2 receptor $\alpha$-chain ${ }^{\circ}$ & P01589 & $1 \mathrm{Z} 92^{\mathrm{XR}} 1,2,2 \mathrm{~B} 5 \mathrm{I}^{\mathrm{XR}} 1,2,2 \mathrm{ERJ} \mathrm{XR}_{1,2}$ & $1,2$ (of 2$)$ \\
\hline Interleukin- 15 receptor $\alpha$-chain & Q13261 & $2 \mathrm{ERS}^{\mathrm{NMR}} 1$ & $1($ of 1$)$ \\
\hline
\end{tabular}

a Derived from http://www.bru.ed.ac.uk/ dinesh/ccp-exp.html. The PDB (http://www.rcsb.org/pdb) IDs are followed by a coded footnote (see below) and the relevant module numbers. Citations may be found at the PDB (most are also in the text). NMR: structure solved in solution using NMR; XR: structure solved by $\mathrm{X}$-ray diffraction.

b Solved in complex with C3d.

${ }^{c}$ Solved in complex with adenovirus type 11 knob.

${ }^{d}$ Coordinates available at http://www.bru.ed.ac.uk/ dinesh/ccp-db.html.

${ }^{\mathrm{e}}$ Solved in complex with heparin-derived octasaccharide.

${ }^{\mathrm{f}}$ Solved in complex with suramin.

g This is the structure of intact factor B.

$\mathrm{h}$ This structure also containing a protease domain.

${ }^{\mathrm{i}}$ The fifth, C-terminal domain of beta2-GPI is sCCP like.

$\mathrm{j}$ The rat sequence was expressed for this structural work.

${ }^{\mathrm{k}}$ The first CCP is reported to be disordered.

${ }^{1}$ The mouse sequence was expressed for this structural work.

${ }^{m}$ Solved in complex with astressin.

${ }^{\mathrm{n}}$ This domain is CCP like.

o This is the structure of IL-2-receptor $\alpha$-chain extracellular region complexed to IL-2 - the CCP-like domains are strand swapped.

bination of NMR studies implicated residue 402 in $\mathrm{fH}-7$ as a contributor to recognition of sulphation patterns in GAGs by factor $\mathrm{H}$ (Herbert et al., 2007). This residue corresponds to the AMD-linked SNP - it is a His in at-risk individuals or a Tyr in the not-at-risk phenotype. Binding studies of these $\mathrm{H} / \mathrm{Y}$ variants were less easy to interpret, displaying a significant context dependency. For example, Y402 and H402 variants of fH-7 could be resolved on a heparin column, but $\mathrm{Y}$ and $\mathrm{H}$ variants of intact factor $\mathrm{H}$ were not resolvable (Herbert et al., 2007). In the context of fH-6-8, however, the Y402 variant bound more tightly than the $\mathrm{H} 402$ variant to some types of GAG but relative affinities were reversed for other GAGs (Clark et al., 2006). Further NMR and X-ray studies (unpublished) support the idea that several sub-sites are distributed along the length of factor H CCPs $6-8$, with H/Y402 contributing to just one of them. Thus, this variation likely has a very subtle but potentially critical influ- ence on GAG recognition in the physiological setting of the ageing macula. Again, this effect would have been hard to measure without dissecting out the individual modules and adopting an atomic-resolution structural approach. Superimposed on this differential affinity for specific GAGs displayed by the two allotypic variants, there are differences in their affinity for $\mathrm{C}$-reactive protein (Laine et al., 2007; Sjoberg et al., 2007; Herbert et al., 2007). In this context, it is noteworthy that factor $\mathrm{H}$ might be recruited to apoptotic cells through its affinity for CRP, whereupon it reduces inflammatory complement stimulation (Gershov et al., 2000).

Flexibility between adjacent CCPs would allow an RCA to change shape during the process of performing its biological role. For example, through a major conformational rearrangement, factor $\mathrm{H}$ could marshal its several binding sites for $\mathrm{C} 3 \mathrm{~b}$ and GAGs that are dispersed along its length, ensuring they are jux- 
taposed so as to cooperatively promote efficacy in complement regulation at the host surface. Similarly, in CR1, two apparently remote functional sites (CCPs 1-3 and CCPs 8-10) act synergistically to dismantle the C5-convertase of the classical pathway, implying that they are close in space in the functional conformation of CR1 (Krych-Goldberg et al., 2005). The capacity of neighbouring modules to tilt and twist relative to one another is determined by the extent of favourable interactions between them and also the length and rigidity of the linking sequence that connects them. It is hard to quantify intermodular flexibility from inspection of structures of CCP modules arranged end-to-end within the crystal lattice and sharing relatively small intermodular interfaces. Although NMR is conducted in solution and should therefore be more reliable, some early NMR-determined structures of module pairs might have been under-restrained due to the sparsity of detectable NOE-derived structural restraints between modules (Barlow et al., 1993; Henderson et al., 2001). The more recent use of ${ }^{13} \mathrm{C}$-labelling and multiple sets of residual dipolar couplings has resulted in better convergence amongst ensembles of NMR-derived structures of module pairs (e.g. for C4BP-1,2) (Jenkins et al., 2005). In any case, NMR appears to be size limited to module pairs, and the results obtained for flexibility in isolated pairs cannot necessarily be extrapolated to full-length RCAs containing up to 20 or 30 CCPs.

Current models for DAF mechanism envisage CCPs 2-4 acting as a rigid unit (Harris et al., 2007). According to this model, the role of CCP 3 is to maintain appropriate, fixed orientations of CCPs 2 and 4 such that they contact, respectively, $\mathrm{Bb}$ and the $\mathrm{C} 3 \mathrm{~b}$ components of alternative pathway convertases. On the other hand, evidence is accumulating for the notion of ligand-induced conformational adjustments in many RCAs. In a recent crystal structure of MCP-1-2 complexed with an adenovirus protein (Persson et al., 2007), the module-module angles are different to their values in the free protein. In the crystal structure of VCP complexed with suramin, the CCP 2-3 intermodular angles differ from their equivalents in the free protein (Ganesh et al., 2004). "Straightening" of an initially "curved" fH-6-8 upon binding to a heparin decasaccharide was suggested based on analysis of scattering and sedimentation data (Fernando et al., 2007). When fH-19-20 binds to a heparin tetrasaccharide, resonances assigned to linker residues broaden (Herbert et al., 2006), indicative of changes in the dynamics of intermodular motion. In NMR-based studies of C4BP-1-2, the chemical shift changes accompanying binding to a Streptococcal $\mathrm{M}$ protein are consistent with intermodular conformational changes (Jenkins et al., 2005). For CR2-1-2, the highly tilted (closed-vee) modules observed in the crystal structure of the complex with C3d (Gilbert et al., 2005; Szakonyi et al., 2001) are incompatible with the open-vee structure of nonliganded CR2-1-2 inferred from small angle X-ray scattering and sedimentation studies (Guthridge et al., 2001). However, this story is complex because a crystal structure of the free (noligand) CR2-1-2 exhibits the closed-vee structure (Prota et al., 2002), while solution studies of the complex support the openvee structure (Gilbert et al., 2005). Disparities between crystal and solution structures were also observed for another CCP- containing protein beta-2-glycoprotein I (Bouma et al., 1999; Hammel et al., 2002). Such anomalies could arise from crystal packing and the use of non-physiological crystal-growing conditions.

Thus, flexibility is likely important for activity in some RCAs, and in particular for the larger ones with multiple binding sites such as factor $\mathrm{H}$ and $\mathrm{CR} 1$ (and indeed CR2). In this respect, it is probably no coincidence that engineering of RCAs with residues inserted into linkers normally devastates function, that linker residues and intermodular "joints" of RCAs frequently contribute to intermolecular interactions, and that binding sites are often composite involving sub-sites on adjacent modules (Blom et al., 2000; Brodbeck et al., 2000; Jenkins et al., 2005; Krych-Goldberg and Atkinson, 2001; Krych-Goldberg et al., 2005). By binding at the intermodular linker or across multiple modules, ligands will bridge adjacent modules and modulate the overall structure of an RCA. In this way, one ligand (such as a GAG in the case of factor $\mathrm{H}$ ) can influence the relative positioning of remote binding sites for further ligands (such as $\mathrm{C} 3 \mathrm{~b})$.

In conclusion, despite this wealth of structural information, we have little detailed knowledge of how any of the RCA proteins actually works as an intact entity. The larger the protein, the greater is our ignorance. The determination of structures of $\mathrm{C} 3 \mathrm{~b}$ (see above) bolsters prospects for future structures of RCAs in complex with convertases or their components (Bromek et al., 2005). In the meantime, new approaches are required to stitch together the high-resolution work based on NMR and crystallography with low-resolution approaches such as small-angle X-ray scattering. For example, electron paramagnetic resonance and fluorescence resonance energy transfer can both measure accurately distances in the $50-100 \mathrm{~nm}$ range given suitably labelled proteins (Banham et al., 2006).

\section{Concluding remarks}

The significant efforts put during the past years into the use of structural biology techniques have revealed the structure at atomic resolution of several of the proteins involved in complement activation and regulation, providing valuable insights into some of the intimate mechanisms that underlie the various facets of its function. In many cases, these structures represent instant pictures of proteins that in vivo are likely subject to multiple conformational changes, each associated with a particular step of their operation. Further understanding of these processes will therefore require investigation of the dynamic properties of these proteins. The extensive use of site-directed mutagenesis will also be necessary to fully elucidate these mechanisms. Finally, full integration of structural and functional data will require resolution of the structure of proteins and protein-protein complexes of larger size, as achieved in the case of C3, as well as the use of lower-resolution approaches such as electron microscopy and small-angle X-ray scattering. It may be anticipated that the wealth of data provided by these combined approaches will pave the way for the rational design of new drugs able to combat complement-mediated diseases. 


\section{Acknowledgements}

Bert Janssen and Vengadesan Krishnan are gratefully acknowledged for help and critically reading the review.

\section{References}

Aoyagi, Y., Adderson, E.E., Min, J.G., Matsushita, M., Fujita, T., Takahashi, S., Okuwaki, Y., Bohnsack, J.F., 2005. Role of L-ficolin/mannose-binding lectin associated serine protease complexes in the opsonophagocytosis of type III group B streptococci. J. Immunol. 174, 418-425.

Arlaud, G.J., Volanakis, J.E., Thielens, N.M., Narayana, S.V., Rossi, V., Xu, Y., 1998. The atypical serine proteases of the complement system. Adv. Immunol. 69, 249-307.

Aslam, M., Perkins, S.J., 2001. Folded-back solution structure of monomeric factor $\mathrm{H}$ of human complement by synchrotron $\mathrm{X}$-ray and neutron scattering, analytical ultracentrifugation and constrained molecular modelling. J. Mol. Biol. 309, 1117-1138.

Banham, J.E., Timmel, C.R., Abbott, R.J., Lea, S.M., Jeschke, G., 2006. The characterization of weak protein-protein interactions: evidence from DEER for the trimerization of a von Willebrand Factor A domain in solution. Angew. Chem. Int. Ed. Engl. 45, 1058-1061.

Barlow, P.N., Baron, M., Norman, D.G., Day, A.J., Willis, A.C., Sim, R.B., Campbell, I.D., 1991. Secondary structure of a complement control protein module by two-dimensional 1H NMR. Biochemistry 30, 997-1004.

Barlow, P.N., Norman, D.G., Steinkasserer, A., Horne, T.J., Pearce, J., Driscoll, P.C., Sim, R.B., Campbell, I.D., 1992. Solution structure of the fifth repeat of factor $\mathrm{H}$ : a second example of the complement control protein module. Biochemistry 31, 3626-3634.

Barlow, P.N., Steinkasserer, A., Norman, D.G., Kieffer, B., Wiles, A.P., Sim, R.B., Campbell, I.D., 1993. Solution structure of a pair of complement modules by nuclear magnetic resonance. J. Mol. Biol. 232, 268-284.

Becherer, J.D., Alsenz, J., Esparza, I., Hack, C.E., Lambris, J.D., 1992. Segment spanning residues $727-768$ of the complement $\mathrm{C} 3$ sequence contains a neoantigenic site and accommodates the binding of $\mathrm{CR} 1$, factor $\mathrm{H}$, and factor B. Biochemistry 31, 1787-1794.

Bhattacharya, A.A., Lupher Jr., M.L., Staunton, D.E., Liddington, R.C., 2004. Crystal structure of the A domain from complement factor B reveals an integrin-like open conformation. Structure 12, 371-378.

Blom, A.M., Zadura, A.F., Villoutreix, B.O., Dahlback, B., 2000. Positively charged amino acids at the interface between alpha-chain CCP1 and CCP2 of C4BP are required for regulation of the classical C3-convertase. Mol. Immunol. 37, 445-453.

Bork, P., Downing, A.K., Kieffer, B., Campbell, I.D., 1996. Structure and distribution of modules in extracellular proteins. Q. Rev. Biophys. 29, 119-1167.

Bouma, B., de Groot, P.G., van den Elsen, J.M., Ravelli, R.B., Schouten, A., Simmelink, M.J., Derksen, R.H., Kroon, J., Gros, P., 1999. Adhesion mechanism of human beta(2)-glycoprotein I to phospholipids based on its crystal structure. EMBO J. 18, 5166-5174.

Bramham, J., Thai, C.T., Soares, D.C., Uhrin, D., Ogata, R.T., Barlow, P.N., 2005. Functional insights from the structure of the multifunctional C $345 \mathrm{C}$ domain of C5 of complement. J. Biol. Chem. 280, 10636-10645.

Brodbeck, W.G., Kuttner-Kondo, L., Mold, C., Medof, M.E., 2000. Structure/function studies of human decay-accelerating factor. Immunology 101, 104-111.

Bromek, K., Lee, D., Hauhart, R., Krych-Goldberg, M., Atkinson, J.P., Barlow, P.N., Pervushin, K., 2005. Polychromatic selective population inversion for TROSY experiments with large proteins. J. Am. Chem. Soc. 127, 405-411.

Brook, E., Herbert, A.P., Jenkins, H.T., Soares, D.C., Barlow, P.N., 2005. Opportunities for new therapies based on the natural regulators of complement activation. Ann. N.Y. Acad. Sci. 1056, 176-188.

Budayova-Spano, M., Lacroix, M., Thielens, N.M., Arlaud, G.J., FontecillaCamps, J.C., Gaboriaud, C., 2002a. The crystal structure of the zymogen catalytic domain of complement protease $\mathrm{C} 1 \mathrm{r}$ reveals that a disruptive mechanical stress is required to trigger activation of the $\mathrm{C} 1$ complex. EMBO J. 21, 231-239.
Budayova-Spano, M., Grabarse, W., Thielens, N.M., Hillen, H., Lacroix, M., Schmidt, M., Fontecilla-Camps, J.C., Arlaud, G.J., Gaboriaud, C., 2002 b. Monomeric structures of the zymogen and active catalytic domains of complement protease $\mathrm{C} 1 \mathrm{r}$ : further insights into the $\mathrm{C} 1$ activation mechanism. Structure 10, 1509-1519.

Casasnovas, J.M., Larvie, M., Stehle, T., 1999. Crystal structure of two CD46 domains reveals an extended measles virus-binding surface. EMBO J. 18, 2911-2922.

Clark, S.J., Higman, V.A., Mulloy, B., Perkins, S.J., Lea, S.M., Sim, R.B., Day, A.J., 2006. H384 allotypic variant of factor $\mathrm{H}$ associated with age-related macular degeneration has different heparin-binding properties from the nondisease-associated form. J. Biol. Chem. 281, 24713-24720.

Fernando, A.N., Furtado, P.B., Clark, S.J., Gilbert, H.E., Day, A.J., Sim, R.B., Perkins, S.J., 2007. Associative and structural properties of the region of complement factor $\mathrm{H}$ encompassing the Tyr402His disease-related polymorphism and its interactions with heparin. J. Mol. Biol. 368, 564-581.

Ferreira, V.P., Herbert, A.P., Hocking, H.G., Barlow, P.N., Pangburn, M.K., 2006. Critical role of the $\mathrm{C}$-terminal domains of factor $\mathrm{H}$ in regulating complement activation at cell surfaces. J. Immunol. 177, 6308-6316.

Fishelson, Z., 1991. Complement C3: a molecular mosaic of binding sites. Mol. Immunol. 28, 545-552.

Fredslund, F., Jenner, L., Husted, L.B., Nyborg, J., Andersen, G.R., SottrupJensen, L., 2006. The structure of bovine complement component 3 reveals the basis for thioester function. J. Mol. Biol. 361, 115-127.

Gaboriaud, C., Juanhuix, J., Gruez, A., Lacroix, M., Darnault, C., Pignol, D., Verger, D., Fontecilla-Camps, J.C., Arlaud, G.J., 2003. The crystal structure of the globular head of complement protein C1q provides a basis for its versatile recognition properties. J. Biol. Chem. 278, 46974-46982.

Gaboriaud, C., Thielens, N.M., Gregory, L.A., Rossi, V., Fontecilla-Camps, J.C., Arlaud, G.J., 2004. Structure and activation of the C1 complex of complement: unravelling the puzzle. Trends Immunol. 25, 68-73.

Ganesh, V.K., Smith, S.A., Kotwal, G.J., Murthy, K.H., 2004. Structure of vaccinia complement protein in complex with heparin and potential implications for complement regulation. Proc. Natl. Acad. Sci. U. S. A. 101, 8924-8929.

Garlatti, V., Belloy, N., Martin, L., Lacroix, M., Matsushita, M., Endo, Y., Fujita, T., Fontecilla-Camps, J.C., Arlaud, G.J., Thielens, N.M., Gaboriaud, C., 2007. Structural insights into the innate immune recognition specificities of L- and H-ficolins. EMBO J. 26, 623-633.

Gershov, D., Kim, S., Brot, N., Elkon, K.B., 2000. C-Reactive protein binds to apoptotic cells, protects the cells from assembly of the terminal complement components, and sustains an antiinflammatory innate immune response: implications for systemic autoimmunity. J. Exp. Med. 192, 1353-1364.

Gilbert, H.E., Eaton, J.T., Hannan, J.P., Holers, V.M., Perkins, S.J., 2005. Solution structure of the complex between CR2 SCR 1-2 and C3d of human complement: an X-ray scattering and sedimentation modelling study. J. Mol. Biol. 346, 859-873.

Gilbert, H.E., Asokan, R., Holers, V.M., Perkins, S.J., 2006. The 15 SCR flexible extracellular domains of human complement receptor type 2 can mediate multiple ligand and antigen interactions. J. Mol. Biol. 362, 1132-1147.

Gordon, D.L., Kaufman, R.M., Blackmore, T.K., Kwong, J., Lublin, D.M., 1995. Identification of complement regulatory domains in human factor $\mathrm{H}$. J. Immunol. 155, 348-356.

Gregory, L.A., Thielens, N.M., Arlaud, G.J., Fontecilla-Camps, J.C., Gaboriaud, C., 2003. X-ray structure of the $\mathrm{Ca}^{2+}$-binding domain of C1s. Insights into the assembly of the $\mathrm{C} 1$ complex of complement. J. Biol. Chem. 278, 32157-32164.

Guthridge, J.M., Rakstang, J.K., Young, K.A., Hinshelwood, J., Aslam, M., Robertson, A., Gipson, M.G., Sarrias, M.R., Moore, W.T., Meagher, M., Karp, D., Lambris, J.D., Perkins, S.J., Holers, V.M., 2001. Structural studies in solution of the recombinant $\mathrm{N}$-terminal pair of short consensus/complement repeat domains of complement receptor type 2(CR2/CD21) and interactions with its ligand C3dg. Biochemistry 40, 5931-5941.

Hageman, G.S., Anderson, D.H., Johnson, L.V., Hancox, L.S., Taiber, A.J., Hardisty, L.I., Hageman, J.L., Stockman, H.A., Borchardt, J.D., Gehrs, K.M., Smith, R.J., Silvestri, G., Russell, S.R., Klaver, C.C., Barbazetto, I., Chang, S., Yannuzzi, L.A., Barile, G.R., Merriam, J.C., Smith, R.T., Olsh, A.K., Bergeron, J., Zernant, J., Merriam, J.E., Gold, B., Dean, M., Allikmets, R., 2005. A common haplotype in the complement regulatory gene factor 
$\mathrm{H}$ (HF1/CFH) predisposes individuals to age-related macular degeneration. Proc. Natl. Acad. Sci. U. S. A. 102, 7227-7232.

Hammel, M., Kriechbaum, M., Gries, A., Kostner, G.M., Laggner, P., Prassl, R., 2002. Solution structure of human and bovine beta(2)-glycoprotein I revealed by small-angle X-ray scattering. J. Mol. Biol. 321, 85-97.

Harris, C.L., Pettigrew, D.M., Lea, S.M., Morgan, B.P., 2007. Decayaccelerating factor must bind both components of the complement alternative pathway C 3 convertase to mediate efficient decay. J. Immunol. 178, 352-359.

Henderson, C.E., Bromek, K., Mullin, N.P., Smith, B.O., Uhrin, D., Barlow, P.N., 2001. Solution structure and dynamics of the central CCP module pair of a poxvirus complement control protein. J. Mol. Biol. 307, 323-339.

Herbert, A.P., Uhrin, D., Lyon, M., Pangburn, M.K., Barlow, P.N., 2006. Diseaseassociated sequence variations congregate in a polyanion recognition patch on human factor $\mathrm{H}$ revealed in three-dimensional structure. J. Biol. Chem. 281, 16512-16520.

Herbert, A.P., Deakin, J.A., Schmidt, C.Q., Blaum, B.S., Egan, C., Ferreira, V.P., Pangburn, M.K., Lyon, M., Uhrin, D., Barlow, P.N., 2007. Structure shows that a glycosaminoglycan- and protein-recognition site in factor $\mathrm{H}$ is perturbed by age-related macular degeneration-linked SNP. J. Biol. Chem. $282,18960-18968$.

Huber, R., Scholze, H., Paques, E.P., Deisenhofer, J., 1980. Crystal structure analysis and molecular model of human C3a anaphylatoxin. Hoppe Seylers Z. Physiol. Chem. 361, 1389-1399.

Janssen, B.J., Huizinga, E.G., Raaijmakers, H.C., Roos, A., Daha, M.R., NilssonEkdahl, K., Nilsson, B., Gros, P., 2005. Structures of complement component C3 provide insights into the function and evolution of immunity. Nature 437, 505-511.

Janssen, B.J., Christodoulidou, A., McCarthy, A., Lambris, J.D., Gros, P., 2006. Structure of $\mathrm{C} 3 \mathrm{~b}$ reveals conformational changes that underlie complement activity. Nature 444, 213-216.

Jenkins, H.T., Mark, L., Ball, G., Persson, J., Lindahl, G., Uhrin, D., Blom, A.M., Barlow, P.N., 2005. Human C4b-binding protein—structural basis for interaction with Streptococcal M protein, a major bacterial virulence factor. J. Biol. Chem. 281, 3690-3697.

Jenner, L., Husted, L., Thirup, S., Sottrup-Jensen, L., Nyborg, J., 1998. Crystal structure of the receptor-binding domain of alpha 2-macroglobulin. Structure 6, 595-604.

Jokiranta, T.S., Hellwage, J., Koistinen, V., Zipfel, P.F., Meri, S., 2000. Each of the three binding sites on complement factor $\mathrm{H}$ interacts with a distinct site on C3b. J. Biol. Chem. 275, 27657-27662.

Jokiranta, T.S., Jaakola, V.P., Lehtinen, M.J., Parepalo, M., Meri, S., Goldman, A., 2006. Structure of complement factor $\mathrm{H}$ carboxyl-terminus reveals molecular basis of atypical haemolytic uremic syndrome. EMBO J. 25, 1784-1794.

Kairies, N., Beisel, H.G., Fuentes-Prior, P., Tsuda, R., Muta, T., Iwanaga, S., Bode, W., Huber, R., Kawabata, S.I., 2001. The 2.0-A crystal structure of tachylectin 5A provides evidence for the common origin of the innate immunity and the blood coagulation systems. Proc. Natl. Acad. Sci. U. S. A. 98, 13519-13524.

Kirkitadze, M.D., Barlow, P.N., 2001. Structure and flexibility of the multiple domain proteins that regulate complement activation. Immunol. Rev. 180, 146-161.

Krarup, A., Thiel, S., Hansen, A., Fujita, T., Jensenius, J.C., 2004. L-Ficolin is a pattern recognition molecule specific for acetyl groups. J. Biol. Chem. 279, 47513-47519.

Krarup, A., Sorensen, U.B., Matsushita, M., Jensenius, J.C., Thiel, S., 2005. Effect of capsulation of opportunistic pathogenic bacteria on binding of the pattern recognition molecules mannan-binding lectin, $\mathrm{L}$-ficolin, and $\mathrm{H}$ ficolin. Infect. Immun. 73, 1052-1060.

Krishnan, V., Xu, Y., Macon, K., Volanakis, J.E., Narayana, S.V., 2007. The crystal structure of $\mathrm{C} 2 \mathrm{a}$, the catalytic fragment of classical pathway C3 and C5 convertases of human complement. J. Mol. Biol. 367, 224233.

Krych-Goldberg, M., Atkinson, J.P., 2001. Structure-function relationships of complement receptor type 1. Immunol. Rev. 180, 112-122.

Krych-Goldberg, M., Hauhart, R.E., Porzukowiak, T., Atkinson, J.P., 2005. Synergy between two active sites of human complement receptor type 1 (CD35) in complement regulation: implications for the structure of the classical path- way C3 convertase and generation of more potent inhibitors. J. Immunol. $175,4528-4535$.

Lacroix, M., Rossi, V., Gaboriaud, C., Chevallier, S., Jaquinod, M., Thielens, N.M., Gagnon, J., Arlaud, G.J., 1997. Structure and assembly of the catalytic region of human complement protease $\mathrm{C} 1 \mathrm{r}$ : a three-dimensional model based on chemical cross-linking and homology modelling. Biochemistry 36, 6270-6282.

Lacroix, M., Ebel, C., Kardos, J., Dobo, J., Gal, P., Zavodszky, P., Arlaud, G.J., Thielens, N.M., 2001. Assembly and enzymatic properties of the catalytic domain of human complement protease C1r. J. Biol. Chem. 276, 36233-36240.

Laine, M., Jarva, H., Seitsonen, S., Haapasalo, K., Lehtinen, M.J., Lindeman, N., Anderson, D.H., Johnson, P.T., Jarvela, I., Jokiranta, T.S., Hageman, G.S., Immonen, I., Meri, S., 2007. Y402H polymorphism of complement factor $\mathrm{H}$ affects binding affinity to C-reactive protein. J. Immunol. 178, 3831-3836.

Lambris, J.D., Lao, Z., Oglesby, T.J., Atkinson, J.P., Hack, C.E., Becherer, J.D., 1996. Dissection of CR1, factor H, membrane cofactor protein, and factor B binding and functional sites in the third complement component. J. Immunol. $156,4821-4832$.

Law, S.K., Dodds, A.W., 1997. The internal thioester and the covalent binding properties of the complement proteins C3 and C4. Protein Sci. 6, 263-274.

Lukacik, P., Roversi, P., White, J., Esser, D., Smith, G.P., Billington, J., Williams, P.A., Rudd, P.M., Wormald, M.R., Harvey, D.J., Crispin, M.D., Radcliffe, C.M., Dwek, R.A., Evans, D.J., Morgan, B.P., Smith, R.A., Lea, S.M., 2004. Complement regulation at the molecular level: the structure of decayaccelerating factor. Proc. Natl. Acad. Sci. U. S. A. 101, 1279-1284.

Lynch, N.J., Roscher, S., Hartung, T., Morath, S., Matsushita, M., Maennel, D.N., Kuraya, M., Fujita, T., Schwaeble, W.J., 2004. L-Ficolin specifically binds to lipoteichoic acid, a cell wall constituent of gram-positive bacteria, and activates the lectin pathway of complement. J. Immunol. 172, 1198-1202.

Ma, Y.G., Cho, M.H., Zhao, M., Park, J.W., Matsushita, M., Fujita, M., Lee, B., 2004. Human mannose-binding lectin and L-ficolin function as specific pattern recognition proteins in the lectin pathway of complement. J. Biol. Chem. 279, 25307-25312.

Matsushita, M., Fujita, T., 2001. Ficolins and the lectin complement pathway. Immunol. Rev. 180, 78-85.

Meri, S., Pangburn, M.K., 1994. Regulation of alternative pathway complement activation by glycosaminoglycans: specificity of the polyanion binding site on factor H. Biochem. Biophys. Res. Commun. 198, 52-59.

Milder, F.J., Raaijmakers, H.C., Vandeputte, M.D., Schouten, A., Huizinga, E.G., Romijn, R.A., Hemrika, W., Roos, A., Daha, M.R., Gros, P., 2006. Structure of complement component C2a: implications for convertase formation and substrate binding. Structure 14, 1587-1597.

Milder, F.J., Gomes, L., Schouten, A., Janssen, B.J., Huizinga, E.G., Romijn, R.A., Hemrika, W., Roos, A., Daha, M.R., Gros, P., 2007. Factor B structure provides insights into activation of the central protease of the complement system. Nat. Struct. Mol. Biol. 14, 224-228.

Morgan, B.P., Harris, C.L., 2003. Complement therapeutics; history and current progress. Mol. Immunol. 40, 159-170.

Murthy, K.H., Smith, S.A., Ganesh, V.K., Judge, K.W., Mullin, N., Barlow, P.N., Ogata, C.M., Kotwal, G.J., 2001. Crystal structure of a complement control protein that regulates both pathways of complement activation and binds heparan sulfate proteoglycans. Cell 104, 301-311.

Nagar, B., Jones, R.G., Diefenbach, R.J., Isenman, D.E., Rini, J.M., 1998. X-ray crystal structure of $\mathrm{C} 3 \mathrm{~d}$ : a C3 fragment and ligand for complement receptor 2. Science $280,1277-1281$.

Narayana, S.V., Carson, M., El-Kabbani, O., Kilpatrick, J.M., Moore, D., Chen, X., Bugg, C.E., Volanakis, J.E., DeLucas, L.J., 1994. Structure of human factor D. A complement system protein at 2.0 Á resolution. J. Mol. Biol. 235, 695-708.

Nishida, N., Walz, T., Springer, T.A., 2006. Structural transitions of complement component $\mathrm{C} 3$ and its activation products. Proc. Natl. Acad. Sci. U. S. A. 103, 19737-19742.

Norman, D.G., Barlow, P.N., Baron, M., Day, A.J., Sim, R.B., Campbell, I.D., 1991. Three-dimensional structure of a complement control protein module in solution. J. Mol. Biol. 219, 717-725.

Oran, A.E., Isenman, D.E., 1999. Identification of residues within the 727-767 segment of human complement component $\mathrm{C} 3$ important for its interaction 
with factor $\mathrm{H}$ and with complement receptor 1 (CR1, CD35). J. Biol. Chem. $274,5120-5130$.

Ormsby, R.J., Jokiranta, T.S., Duthy, T.G., Griggs, K.M., Sadlon, T.A., Giannakis, E., Gordon, D.L., 2006. Localization of the third heparin-binding site in the human complement regulator factor H(1). Mol. Immunol. 43, $1624-1632$

Pangburn, M.K., 2000. Host recognition and target differentiation by factor $\mathrm{H}$, a regulator of the alternative pathway of complement. Immunopharmacology 49, 149-157.

Persson, B.D., Reiter, D.M., Marttila, M., Mei, Y.F., Casasnovas, J.M., Arnberg, N., Stehle, T., 2007. Adenovirus type 11 binding alters the conformation of its receptor CD46. Nat. Struct. Mol. Biol. 14, 164-166.

Ponnuraj, K., Xu, Y., Macon, K., Moore, D., Volanakis, J.E., Narayana, S.V., 2004. Structural analysis of engineered $\mathrm{Bb}$ fragment of complement factor $\mathrm{B}$ : insights into the activation mechanism of the alternative pathway C3convertase. Mol. Cell 14, 17-28.

Poon, P.H., Schumaker, V.N., Phillips, M.L., Strang, C.J., 1983. Conformation and restricted segmental flexibility of $\mathrm{C} 1$, the first component of human complement. J. Mol. Biol. 168, 563-577.

Prota, A.E., Sage, D.R., Stehle, T., Fingeroth, J.D., 2002. The crystal structure of human CD21: implications for Epstein-Barr virus and C3d binding. Proc. Natl. Acad. Sci. U. S. A. 99, 10641-10646.

Reid, K.B., Day, A.J., 1989. Structure-function relationships of the complement components. Immunol. Today 10, 177-180.

Rickert, M., Wang, X., Boulanger, M.J., Goriatcheva, N., Garcia, K.C., 2005. The structure of interleukin-2 complexed with its alpha receptor. Science 308, 1477-1480.

Ripoche, J., Day, A.J., Willis, A.C., Belt, K.T., Campbell, R.D., Sim, R.B., 1986. Partial characterization of human complement factor $\mathrm{H}$ by protein and cDNA sequencing: homology with other complement and non-complement proteins. Biosci. Rep. 6, 65-72.

Rodriguez de Cordoba, S., Esparza-Gordillo, J., Goicoechea de Jorge, E., LopezTrascasa, M., Sanchez-Corral, P., 2004. The human complement factor H: functional roles, genetic variations and disease associations. Mol. Immunol. 41, 355-367.

Sharma, A.K., Pangburn, M.K., 1996. Identification of three physically and functionally distinct binding sites for $\mathrm{C} 3 \mathrm{~b}$ in human complement factor $\mathrm{H}$ by deletion mutagenesis. Proc. Natl. Acad. Sci. U. S. A. 93, 10996-11001.

Sheriff, S., Chang, C.Y., Ezekowitz, R.A.B., 1994. Human mannose-binding protein carbohydrate recognition domain trimerizes through a triple $\alpha$-helical coiled-coil. Nat. Struct. Biol. 1, 789-794.

Sjoberg, A.P., Trouw, L.A., Clark, S.J., Sjolander, J., Heinegard, D., Sim, R.B., Day, A.J., Blom, A.M., 2007. The factor H variant associated with agerelated macular degeneration $(\mathrm{H} 384)$ and the non-disease associated form bind differentially to C-reactive protein, fibromodulin, DNA and necrotic cells. J. Biol. Chem. 282, 10894-10900.

Smith, B.O., Mallin, R.L., Krych-Goldberg, M., Wang, X., Hauhart, R.E., Bromek, K., Uhrin, D., Atkinson, J.P., Barlow, P.N., 2002. Structure of the C3b binding site of CR1 (CD35), the immune adherence receptor. Cell 108, 769-780.

Soares, D.C., Barlow, P.N., 2005. Complement control protein modules in the regulators of complement activation. In: Morikis, D., Lambris, J.D. (Eds.),
Structural Biology of the Complement System. CRC Press, Taylor \& Francis Group, Boca Raton, pp. 19-62.

Soares, D.C., Gerloff, D.L., Syme, N.R., Coulson, A.F., Parkinson, J., Barlow, P.N., 2005. Large-scale modelling as a route to multiple surface comparisons of the CCP module family. Protein Eng. Des. Sel. 18, 379-388.

Szakonyi, G., Guthridge, J.M., Li, D., Young, K., Holers, V.M., Chen, X.S., 2001. Structure of complement receptor 2 in complex with its C3d ligand. Science 292, 1725-1728.

Taniguchi-Sidle, A., Isenman, D.E., 1994. Interactions of human complement component $\mathrm{C} 3$ with factor $\mathrm{B}$ and with complement receptors type 1 (CR1, CD35) and type $3(\mathrm{CR} 3, \mathrm{CD} 11 \mathrm{~b} / \mathrm{CD} 18)$ involve an acidic sequence at the N-terminus of C3 alpha'-chain. J. Immunol. 153, 5285-5302.

Uhrinova, S., Lin, F., Ball, G., Bromek, K., Uhrin, D., Medof, M.E., Barlow, P.N., 2003. Solution structure of a functionally active fragment of decay-accelerating factor. Proc. Natl. Acad. Sci. U. S. A. 100, 4718 4723.

van den Elsen, J.M., Martin, A., Wong, V., Clemenza, L., Rose, D.R., Isenman, D.E., 2002. X-ray crystal structure of the C4d fragment of human complement component C4. J. Mol. Biol. 322, 1103-1115.

Villiers, C.L., Arlaud, G.J., Colomb, M.G., 1985. Domain structure and associated functions of subcomponents $\mathrm{C} 1 \mathrm{r}$ and $\mathrm{C} 1 \mathrm{~s}$ of the first component of human complement. Proc. Natl. Acad. Sci. U. S. A. 82, 4477-4481.

Volanakis, J.E., Arlaud, G.J., 1998. Complement enzymes. In: Volanakis, J.E., Frank, M.M. (Eds.), The Human Complement System in Health and Disease. Marcel Dekker, New York, pp. 49-81.

Volanakis, J.E., Narayana, S.V., 1996. Complement factor D, a novel serine protease. Protein Sci. 5, 553-564.

Warwicker, P., Goodship, T.H., Donne, R.L., Pirson, Y., Nicholls, A., Ward, R.M., Turnpenny, P., Goodship, J.A., 1998. Genetic studies into inherited and sporadic hemolytic uremic syndrome. Kidney Int. 53, 836-844.

Weis, W.I., Drickamer, K., 1994. Trimeric structure of a C-type mannose-binding protein. Structure 2, 1227-1240.

Weiss, V., Fauser, C., Engel, J., 1986. Functional model of subcomponent C1 of human complement. J. Mol. Biol. 189, 573-581.

Wiesmann, C., Katschke, K.J., Yin, J., Helmy, K.Y., Steffek, M., Fairbrother, W.J., McCallum, S.A., Embuscado, L., DeForge, L., Hass, P.E., van Lookeren Campagne, M., 2006. Structure of C3b in complex with CRIg gives insights into regulation of complement activation. Nature 444, $217-$ 220.

Xu, Y., Circolo, A., Jing, H., Wang, Y., Narayana, S.V., Volanakis, J.E., 2000. Mutational analysis of the primary substrate specificity pocket of complement factor B. Asp(226) is a major structural determinant for $\mathrm{P}(1)$-Arg binding. J. Biol. Chem. 275, 378-385.

Zanotti, G., Bassetto, A., Battistutta, R., Folli, C., Arcidiaco, P., Stoppini, M., Berni, R., 2000. Structure at $1.44 \AA$ resolution of an N-terminally truncated form of the rat serum complement $\mathrm{C} 3 \mathrm{~d}$ fragment. Biochim. Biophys. Acta $1478,232-238$.

Zipfel, P.F., Jokiranta, T.S., Hellwage, J., Koistinen, V., Meri, S., 1999. The factor $\mathrm{H}$ protein family. Immunopharmacology 42, 53-60.

Zuiderweg, E.R., Nettesheim, D.G., Mollison, K.W., Carter, G.W., 1989. Tertiary structure of human complement component $\mathrm{C} 5 \mathrm{a}$ in solution from nuclear magnetic resonance data. Biochemistry 28, 172-185. 